\title{
Netrin-1 Promotes Excitatory Synaptogenesis between Cortical Neurons by Initiating Synapse Assembly
}

\author{
Jennifer S. Goldman, ${ }^{1,2,3}$ Mohammed A. Ashour, ${ }^{1}$ Margaret H. Magdesian, ${ }^{2,4}$ Nicolas X. Tritsch, ${ }^{1}$ Stephanie N. Harris, ${ }^{1}$ \\ Nicolas Christofi, ${ }^{1}$ Raja Chemali, ${ }^{1}$ Yaakov E. Stern, ${ }^{1}$ Greta Thompson-Steckel, ${ }^{1,2}$ Pavel Gris, ${ }^{1}$ Stephen D. Glasgow, ${ }^{1}$ \\ Peter Grutter, ${ }^{2,4}$ Jean-Francois Bouchard, ${ }^{1}$ Edward S. Ruthazer, ${ }^{1,2}$ David Stellwagen, ${ }^{3}$ and Timothy E. Kennedy ${ }^{1,2}$ \\ ${ }^{1}$ Montreal Neurological Institute, Department of Neurology and Neurosurgery, and ${ }^{2}$ McGill Program in NeuroEngineering, McGill University, Montreal, \\ Quebec, Canada, H3A 2B4, ${ }^{3}$ Centre for Research in Neuroscience, Department of Neurology and Neurosurgery, The Research Institute of the McGill \\ University Health Centre, Montreal General Hospital, Montreal, Quebec, Canada, H3G 1A4, and ${ }^{4}$ Department of Physics, McGill University, Montreal, \\ Quebec, Canada, H3A 2T8
}

Netrin-1 is a secreted protein that directs long-range axon guidance during early stages of neural circuit formation and continues to be expressed in the mammalian forebrain during the postnatal period of peak synapse formation. Here we demonstrate a synaptogenic function of netrin-1 in rat and mouse cortical neurons and investigate the underlying mechanism. We report that netrin-1 and its receptor DCC are widely expressed by neurons in the developing mammalian cortex during synapse formation and are enriched at synapses in vivo. We detect DCC protein distributed along the axons and dendrites of cultured cortical neurons and provide evidence that newly translated netrin-1 is selectively transported to dendrites. Using gain and loss of function manipulations, we demonstrate that netrin-1 increases the number and strength of excitatory synapses made between developing cortical neurons. We show that netrin-1 increases the complexity of axon and dendrite arbors, thereby increasing the probability of contact. At sites of contact, netrin-1 promotes adhesion, while locally enriching and reorganizing the underlying actin cytoskeleton through Src family kinase signaling and m-Tor-dependent protein translation to locally cluster presynaptic and postsynaptic proteins. Finally, we demonstrate using whole-cell patch-clamp electrophysiology that netrin-1 increases the frequency and amplitude of mEPSCs recorded from cortical pyramidal neurons. These findings identify netrin-1 as a synapse-enriched protein that promotes synaptogenesis between mammalian cortical neurons.

\section{Introduction}

During early postnatal development, neurons in the mammalian cerebral cortex elaborate axons and dendrites that connect at synapses to form functional circuits. At nascent synapses, the juxtaposed membrane domains of the axon and dendrite adhere and enrich synaptic molecules specialized for neurotransmission (Waites et al., 2005). On both sides of the synapse, the actin cytoskeleton supports the architecture and function of specialized synaptic domains, buttressing filopodial protrusions, tether-

Received March 12, 2013; revised Sept. 10, 2013; accepted Sept. 23, 2013.

Author contributions: J.S.G., P. Gris., P. Gutter, E.S.R., D.S., and T.E.K. designed research; J.S.G., M.A.A., M.H.M. N.X.T., S.N.H., N.C., R.C., Y.E.S., G.T.-S., and J.-F.B. performed research;J.S.G., P.Gris, and S.D.G. analyzed data;J.S.G., E.S.R., D.S., and T.E.K. wrote the paper.

J.S.G. was supported by fellowships from the Alzheimer's Society of Canada, the McGill Program in NeuroEngineering, and the Ann and Richard Sievers Foundation. J.-F.B. was supported by an Le Fonds de la Recherche en Santé de Québec (FRSQ) Chercheur Boursier Junior 2 scholar award and T.E.K. was supported by an FRSQ Chercheur Nationaux award and a Killam Foundation Scholar award. The project was supported by grants (T.E.K.) from the Canadian Institutes of Health Research (CIHR) and to the McGill Program in NeuroEngineering from CIHR and Natural Sciences and Engineering Research Council of Canada. We thank Keith Murai, Anna Lisa Lucido, Horia Pribiag, Haider Altimimi, Laurent Methot, Neil Schwartz, Wayne Sossin, and Peter McPherson for helpful discussion and technical assistance related to this manuscript.

The authors declare no competing financial interests.

Correspondence should be addressed to Timothy E. Kennedy, Montreal Neurological Institute, 3801 University Street, McGill University, Montreal, Quebec, Canada, H3A 2B4. E-mail: timothy.kennedy@mcgill.ca.

DOI:10.1523/JNEUROSCI.1085-13.2013

Copyright $\odot 2013$ the authors $\quad 0270-6474 / 13 / 3317278-12 \$ 15.00 / 0$ ing transmembrane adhesion molecules, and scaffolding synaptic proteins (Dillon and Goda, 2005; Gallo, 2013).

Netrin-1 is an $\sim 75 \mathrm{kDa}$ secreted protein with homology to laminins (Moore et al., 2007; Lai Wing Sun et al., 2011). It was initially described as an axonal chemoattractant in the embryonic CNS (Kennedy et al., 1994), a role conserved from invertebrates to mammals (Moore et al., 2007; Lai Wing Sun et al., 2011). Subsequently, netrin-1 has been found to regulate growth, branching, cell-adhesion, and the architecture of polarized cellular domains in multiple tissues during development (Lai Wing Sun et al., 2011), in many cases by organizing the actin cytoskeleton via intracellular signaling downstream of the transmembrane receptor Deleted in Colorectal Cancer (DCC).

Genetic analyses in Drosophila melanogaster initially implicated netrin secreted by muscle cells as a target-derived regulator of neuromuscular synapse formation (Mitchell et al., 1996). Studies in Caenorhabditis elegans demonstrated that secretion of the netrin-1 ortholog Unc- 6 by glial guidepost cells or by postsynaptic neurons directs the formation of presynaptic specializations through a mechanism dependent on Unc-40, the nematode ortholog of DCC (Colón-Ramos et al., 2007; Park et al., 2011; Stavoe and Colon-Ramos, 2012). In Xenopus, application of netrin-1 protein to the optic tectum increases the number of axon branches and presynaptic specializations made by innervating retinal ganglion cells through a DCC-dependent mechanism (Manitt et al., 2009). Netrin-1 also promotes axon branching by 
mammalian embryonic cortical neurons (Dent et al., 2004; Tang and Kalil, 2005) and is expressed in the human cerebral cortex during development (Harter et al., 2010), raising the possibility that synaptogenic functions of netrin-1 are conserved.

Here, we demonstrate that netrin-1 and DCC are expressed by neurons in rodent cortex during the early postnatal period of synapse formation, in vivo. We show that newly synthesized netrin-1 protein is targeted to dendrites, while DCC is distributed along both dendrites and axons. Global gain or loss of netrin-1 function results in rapid and sustained changes in cortical neuron dendrite arbor complexity and modulates the number and function of excitatory synapses by regulating both presynapse and postsynapse formation. Local presentation of netrin-1 to cortical neurons promotes adhesion and the focal accumulation of synaptic proteins through enrichment and reorganization of the actin cytoskeleton downstream of DCC, mTor-dependent mRNA translation, and Src-family kinase (SFK) activation. These findings demonstrate that netrin-1 is a synapse-enriched protein that regulates connectivity between developing cortical neurons.

\section{Materials and Methods}

All procedures were performed in accordance with the Canadian Council on Animal Care guidelines for the use of animals in research.

Animals. Both male and female rats and mice were used at the ages specified in the text. All wild-type and transgenic mice were a CD1 genetic background. All rat studies used the Sprague Dawley strain. $N t n 1^{-1+}$ and $\mathrm{Dcc}^{-1+}$ mice were obtained from Marc Tessier-Lavigne (Rockefeller University, NY) and Robert Weinberg (Harvard University, MA), respectively.

Subcellular fractionation. Cortex from 10 adult mice was dissected and homogenized in ice-cold buffer $(0.32 \mathrm{~m}$ sucrose, $1 \mathrm{~mm} \mathrm{NaHCO} 3,1 \mathrm{~mm}$ $\mathrm{MgCl}_{2}, 0.5 \mathrm{mM} \mathrm{CaCl}_{2}$, aprotinin, leupeptin, and pepstatin) in a Teflonglass homogenizer. Homogenates were fractionated using differential centrifugation as described previously (Huttner et al., 1983). Protein concentration was quantified using a BCA kit (Pierce). Protein was resolved by SDS-PAGE, $10 \mu \mathrm{g} / \mathrm{lane}$, and processed for Western blot analysis. Results were visualized using chemiluminescence (NEN Life Science).

Embryonic cortical neuron cultures. Cell cultures were prepared from cerebral cortex of embryonic day 16-18 (E16-E18) CD1 mice or E18 Sprague Dawley rats as previously described (Goslin and Banker, 1998; Hilgenberg and Smith, 2007). For wild-type cultures, cortex from multiple embryos was pooled and dissociated, whereas cortex from each mutant embryo was independently dissociated and plated. Cells were plated at low density $\left(\sim 2500\right.$ cells $\left./ \mathrm{cm}^{2}\right)$ for analyses of the effects of beads on synaptic protein levels in isolated neurites, at medium density $\left(\sim 15,000 \mathrm{cells} / \mathrm{cm}^{2}\right)$ for imaging synaptic puncta, and for experiments addressing the influence of netrin-adsorbed beads on actin, SFKs, and AHA, and at high density $\left(\sim 40,000\right.$ cells $\left./ \mathrm{cm}^{2}\right)$ for electrophysiology and adhesion assays.

All cultures were maintained for 2-22 d in vitro (DIV) in Neurobasal medium containing 1\% B27, and 2 mm glutamax (and $0.5 \% \mathrm{~N} 2$ for mouse cultures), at $37^{\circ} \mathrm{C}$ in a humidified $5 \% \mathrm{CO}_{2}$ incubator.

For analyses of branching, synaptic puncta, and electrophysiology, cortical neuron cultures were stimulated by adding $150 \mathrm{ng} / \mathrm{ml}$ netrin-1 directly to the culture media. Mouse monoclonal IgG1 DCC function blocking antibody (dfb; $10 \mu \mathrm{g} / \mathrm{ml}$; Calbiochem), mouse monoclonal IgG1 isotype control (10 $\mu \mathrm{g} / \mathrm{ml}$; eBioscience), DCC-fc (5 $\mu \mathrm{g} / \mathrm{ml}$; R\&D Systems), jasplakinolide (10 nM; Sigma-Aldrich), latrunculin-A (5 $\mu \mathrm{M}$; Sigma-Aldrich), PP2 and PP3 ( $2 \mu \mathrm{M}$; Sigma-Aldrich), and rapamycin (20 nм; Sigma-Aldrich) were added to the media 15 min before netrin-1 stimulation or the addition of netrin-1 adsorbed microspheres. Cortical neurons were transfected using Lipofectamine 2000 (Invitrogen) with cDNAs encoding netrin-1-myc (Kennedy et al., 1994) or eGFP-f or infected with semliki forest virus expressing eGFP-f (gift from Keith Murai, McGill University, Canada; Zhou et al., 2007).

Preparation of microspheres. Microspheres (7.32 $\mu \mathrm{m}$ polystyrene; Bangs Beads) were washed $3 \times$ in PBS (sterile, $\mathrm{pH}$ 7.4) before use. Re- combinant netrin-1 protein $(10 \mu \mathrm{g} / \mathrm{ml})$ or BDNF $(1 \mu \mathrm{g} / \mathrm{ml})$ was adsorbed to beads by an overnight incubation and three subsequent washes in PBS to remove unbound protein. Beads were pelleted by centrifugation, $7 \mathrm{~min}$ at $6500 \mathrm{rpm}$, and resuspended in culture media before addition to cortical cultures.

Immunocytochemistry. For immunolabeling in Fig. $1, b-f$, cells were fixed at $37^{\circ} \mathrm{C}$ in $4 \%$ paraformaldehyde (PFA) with $0.1 \%$ glutaraldehyde for 1-2 min. To immunolabel synaptic proteins, cells were fixed in $100 \%$ $\mathrm{MeOH}$ for $8-10 \mathrm{~min}$ at $-20^{\circ} \mathrm{C}$. For the studies shown in Fig. 1i, recombinant netrin- 1 was added for 5 min to cells on ice, which were then fixed with $-20^{\circ} \mathrm{C} 100 \% \mathrm{MeOH}$. For Fig. $1, k$ and $l, \mathrm{P} 21$ mouse brain was fixed by immersion for $1 \mathrm{~h}$ in $4 \%$ PFA, cryoprotected in 30\% sucrose/PBS, embedded in OCT, and $20-\mu \mathrm{m}$-thick sections cut with a cryostat. The following antibodies were used: mouse anti-DCC (BD PharMingen), goat anti-DCC (Santa Cruz Biotechnology), rabbit anti-GluA1 (Millipore Bioscience Research Reagents), chicken anti-MAP2 (GeneTex), mouse 9E10 anti-Myc (Millipore), rabbit anti-netrin-1 11760 (Kennedy et al., 2006), rabbit anti netrin-1 (Abcam), rat anti-netrin-1 (R\&D Systems), rabbit anti-PSD95 (Cell Signaling Technology), mouse antiPSD95 (NeuroMab), rabbit anti-synapsin (Cell Signaling Technology), mouse anti-synaptophysin (Sigma), guinea pig anti-vglut1 (Synaptic Systems), rabbit anti-pY416SFK, and mouse anti-SFK (Cell Signaling Technology). For immunocytochemistry, cells were blocked with 3\% powdered milk, or $3 \%$ bovine serum albumin (BSA) for pY416SFK, with $0.1 \%$ Triton $\mathrm{X}-100$ in $0.1 \mathrm{M}$ PBS, $\mathrm{pH} 7.4$, for $1 \mathrm{~h}$ at room temperature (RT). Antibodies were diluted in blocking solution (1\% milk or BSA, $0.1 \%$ Triton X-100 in $0.1 \mathrm{M}$ PBS, pH 7.4); incubated overnight; and immunolabeling visualized with Alexa Fluor 488-, Alexa Fluor 546-, or Alexa Fluor 633-coupled secondary antibodies (Invitrogen). For imaging F-actin in conjunction with antibody staining, phalloidin A647 (Invitrogen) was incubated with secondary antibodies. To enhance the visualization of F-actin, cells were fixed in cytoskeleton buffer ( $10 \mathrm{~mm}$ MES, $3 \mathrm{~mm}$ $\mathrm{MgCl}^{2}, 138 \mathrm{~mm} \mathrm{KCl}, 2$ mu EGTA, $0.32 \mathrm{~m}$ sucrose, 4\% PFA, $\mathrm{pH}$ 6) for 15 min at RT, washed in PBS, permeabilized in $100 \%$ acetone $\left(-20^{\circ} \mathrm{C}\right)$ for 5 min, washed in PBS, and incubated with A488 phalloidin and A594 DNAase I (Invitrogen) in PBS with $0.1 \%$ Triton X-100. To visualize the synthesis of new protein, dfb, IgG, or rapamycin were added to cells in culture with methionine-free media and Click-it AHA reagent, following the protocol provided by the manufacturer (Sigma-Aldrich), $15 \mathrm{~min}$ before addition of beads. After $10 \mathrm{~min}$ or $30 \mathrm{~min}$ incubation with beads, cells were fixed in 4\% PFA for $15 \mathrm{~min}$.

Analyses of branching and filopodia. Confocal images were captured of eGFP-f transfected neurons with pyramidal morphology and the first 30 $\mu \mathrm{m}$ proximal to the soma of the most prominent dendrite were analyzed. Dendritic filopodia were defined as any dendritic protrusion $<15 \mu \mathrm{m}$ in length, traced using ImageJ (National Institutes of Health (NIH) Software;Schneider et al., 2012).

Adhesion assays. Soluble inhibitors were added to the culture media of dissociated cortical neurons $15 \mathrm{~min}$ before the addition of beads and then incubated for $1 \mathrm{~h}$. Wells were washed three times with $37^{\circ} \mathrm{C}$ sterile PBS, $\mathrm{pH} 7.4$, and cells fixed in $4 \%$ PFA, $0.1 \%$ glutaraldehyde for $5 \mathrm{~min}$. The number of beads was counted in washed and unwashed conditions. Values are presented as percentage beads remaining $=$ [\# of beads per field in washed conditions]/[average \# of beads per field in unwashed conditions] ${ }^{\star} 100$.

Atomic force microscopy. Cortical neurons cultured in $35 \mathrm{~mm}$ glassbottom dishes (MatTek Corp) were transfected with cDNAs encoding Synaptophysin-GFP or PSD95-GFP at 6 DIV. Polystyrene $4.5 \mu \mathrm{m}$ diameter beads (Polysciences) were fixed to the tip of silicon nitride probes (MSCT-AUHW; Microlevers; Veeco) with a nominal spring constant of $k=0.01 \mathrm{~N} / \mathrm{m}$ as described previously (Lucido et al., 2009). Before contacting the cells, beaded cantilevers were incubated in HBSS (control beads) or in $10 \mu \mathrm{g} / \mathrm{ml}$ netrin-1 solution in HBSS overnight at $4^{\circ} \mathrm{C}$. Live cell imaging experiments were performed on a Bioscope atomic force microscope (AFM; Digital Instruments, Veeco) mounted on an inverted optical microscope (Axiovert S100 TV; Carl Zeiss) using a $40 \times$ objective (1.3 NA) and $1 \mathrm{k}$ CCD camera (Photometrics). Cells were mounted on a heated stage (Warner Instruments) and held at $37^{\circ} \mathrm{C}$ with $\mathrm{CO}_{2}$ supplied for the duration of the experiments $(\sim 2 \mathrm{~h})$. The AFM was used to posi- 
tion and move the beaded cantilever with submicrometer precision to contact regions of axons or dendrites without synaptic puncta. The force applied with the AFM was limited to $\leq 0.3 \mathrm{nN}$ for $\sim 90 \mathrm{~min}$. Images were taken every minute for 10 min before bead contact to monitor the movement of synaptic proteins and neuronal viability; and for $\sim 90$ min during bead-neuron contact to detect synaptic assembly. Quantification of the area of contact was made for baseline and samples collected following contact. Fluorescence intensity values at any given time are normalized to the average local intensity at baseline.

Synaptic puncta analysis. Images of pyramidal neurons were collected and $30 \mu \mathrm{m}$ of dendrite proximal to the cell soma selected for analysis using ImageJ software (NIH; Schneider et al., 2012). Background was subtracted with a rolling ball with radius $=5$. Images were thresholded using a constant value for each channel, and an image generated using the colocalization highlighter to identify regions of overlap between labeling. Puncta were analyzed in each individual channel and in the colocalization image.

Electrophysiology. Whole-cell patch-clamp recordings were made at RT using an inverted Olympus microscope on medium-sized cortical neurons with pyramidal morphology. The extracellular solution contained the following (in mM): $135 \mathrm{NaCl}, 3.5 \mathrm{KCl}, 1.3 \mathrm{MgCl}_{2}, 2 \mathrm{CaCl}_{2}, 10$ HEPES and 20 D-glucose, and $200 \mathrm{~nm}$ tetrodotoxin. Pipette resistances ranged from 3-5 M $\Omega$. The intracellular electrode solution contained the following in (mM): $125 \mathrm{CsMeSO}_{4}, 15$ HEPES, $10 \mathrm{CsCl}, 1.5 \mathrm{EGTA}$, and $0.15 \mathrm{CaCl}_{2}, 5$ phosphocreatine, $4 \mathrm{MgATP}$, and $0.4 \mathrm{Na}_{3} \mathrm{GTP}$. Recordings were made in voltage-clamp mode with a holding potential of $-70 \mathrm{mV}$. Data were acquired with p-Clamp 10.3 at $5 \mathrm{kHz}$ and filtered at $1 \mathrm{kHz}$. Cells with $<4$ pA peak-to-peak background noise, $\mathrm{Ra}<25 \mathrm{M} \Omega$, with $<20 \%$ change in Ra were analyzed with miniAnalysis software (Synaptosoft). One hundred mEPSCs per cell, 8 cells per condition, were included in the analysis.

Data acquisition and analysis. All data were acquired and analyzed by an individual blind to the experimental conditions. Cell-bead adhesion data were collected using a Carl Zeiss Axiovert microscope and Magnafire CCD camera (Optronics). All other images were captured using a Zeiss LSM 510 or 710 laser scanning confocal microscope. Sister cultures were used in all experiments in which comparisons were made. Images for quantification were captured using the same parameters to allow comparisons to be made between conditions. Data are expressed as mean \pm SEM and analyzed using Systat or SPSS software by $t$ test or one-way ANOVA (for data containing more than one comparison) followed by a post hoc test. All $p$ values represent comparison to control conditions, except where noted in the text. Statistical analyses of the AFM data presented in Figure 6 were assessed using restricted maximum likelihood analysis (REML) as well as repeated-measures ANOVA, and significant differences between baseline and experimental conditions were investigated by pairwise multiple comparisons using the Bonferroni method for parametric data. Additionally, homoscedasticity was assessed using Levene's test for equality of variances. AFM data are presented mean \pm SEM, and were analyzed using built-in and custom routines in Partek GS 6.6 (Partek) and Sigmaplot 11 (Systat).

\section{Results}

Netrin-1 and DCC are expressed by cortical neurons during synaptogenesis and are enriched at synapses

The majority of synaptogenesis between cortical neurons occurs between postnatal days 5-20 (P5-P20) in rat (Micheva and Beaulieu, 1996). To investigate whether netrin-1 and DCC might contribute to cortical synaptogenesis, we initially examined levels of netrin-1 and DCC protein in homogenates derived from rat cortex during development and in adulthood (Fig. 1a). Netrin-1 and DCC were detected in cortical homogenates from E15 through adulthood, with high levels of protein corresponding to the postnatal period of intracortical synaptogenesis (Fig. 1a).

We next examined the subcellular localization of netrin- 1 and DCC in developing cultures of cortical neurons. At 11 DIV, just before robust synapses can be detected, immunolabeling detected endogenous netrin-1 protein broadly associated with Map2positive dendrites and Map2-negative axons (Fig. 1b). Since netrin-1 is secreted, this immunostaining may correspond to intracellular netrin-1 in secretory vesicles or extracellular netrin-1 bound to membrane receptors or extracellular matrix. To examine its initial trafficking, we transfected cortical neurons with a cDNA encoding myc-tagged netrin-1. Netrin-1-myc was readily detected in the somatodendritic compartment at 6,12 , and $36 \mathrm{~h}$ after transfection, but never in the axon (Fig. $1 c, d$ ). DCC is a single pass type 1 transmembrane protein that directs the organization of F-actin (Lai Wing Sun et al., 2011). The distribution of DCC detected by immunolabeling is consistent with trafficking to axons and dendrites (Fig. 1e), and double labeling with phalloidin reveals DCC enriched with F-actin in the filopodia and motile edges of axons and dendrites (Fig. 1e,f).

At $21 \mathrm{DIV}$, immunocytochemical staining reveals substantial overlap between the distributions of endogenous netrin-1, DCC, and markers of excitatory synapses (Fig. $1 g, h$ ). To determine whether netrin-1 binding sites might be associated with synapses, we first incubated cultures of cortical neurons on ice to block endocytosis and then added soluble myc-tagged recombinant netrin-1 protein. Immunostaining for the myc epitope tag revealed substantial overlap between myc-netrin-1 and immunocytochemical markers for synapses (Fig. 1i), consistent with the enrichment of cell surface netrin-1 binding sites at synapses.

To determine whether netrin-1 and DCC may contribute to the assembly of cortical synapses, we assessed if they are present at developing cortical synapses in vivo. We first examined the distribution of netrin-1 and DCC protein following subcellular fractionation of homogenates of P15 cortex. Homogenates were separated into fractions enriched for nuclei and cellular debris (P1), synaptosomes (P2), endoplasmic reticulum (ER) and Golgi microsomes (P3), and cytosolic soluble proteins (S). The P2 fraction was then further fractionated into a synaptic membrane fraction containing presynaptic and postsynaptic membranes (LP1) and a synaptic vesicle fraction that contains vesicles derived from both the presynaptic and postsynaptic compartments (LP2). We found that both netrin-1 and DCC are present in synaptic fractions (P2, LP1, and LP2) (Fig. 1j).

To determine the proportion of synapses containing netrin- 1 or DCC in vivo, we stained for netrin-1 and DCC in conjunction with presynaptic and postsynaptic markers in histological sections prepared from 21-d-old mouse (Fig. $1 k, l$ ). Staining for netrin-1 and DCC overlaps substantially with excitatory synapses. These findings indicate that readily detectable levels of netrin-1 and DCC are present at excitatory synapses in the rat and mouse cortex during the developmental period of synaptogenesis.

\section{Netrin-1 induces rapid and long-lasting changes in filopodia density}

During synapse formation, axons and dendrites become increasingly complex, extending filopodia to connect with synaptic partners. Consistent with previous results (Dent et al., 2004; Tang and Kalil, 2005), we found that netrin-1 increases the number of filopodia along axons (data not shown). In C. elegans and zebrafish, netrin signaling has also been shown to regulate the elaboration of dendrites (Suli et al., 2006; Smith et al., 2012) and postsynaptic membrane extension (Alexander et al., 2009). To determine whether netrin-1 regulates the number of filopodia along the dendrites of cortical neurons, cultures of E18 rat cortex were transfected with a plasmid encoding membrane-targeting farnesylated GFP (eGFP-f) and incubated with netrin-1 (net1) or a netrin-1 function blocking antibody (nfb) for $72 \mathrm{~h}, 24 \mathrm{~h}, 1 \mathrm{~h}$, or 

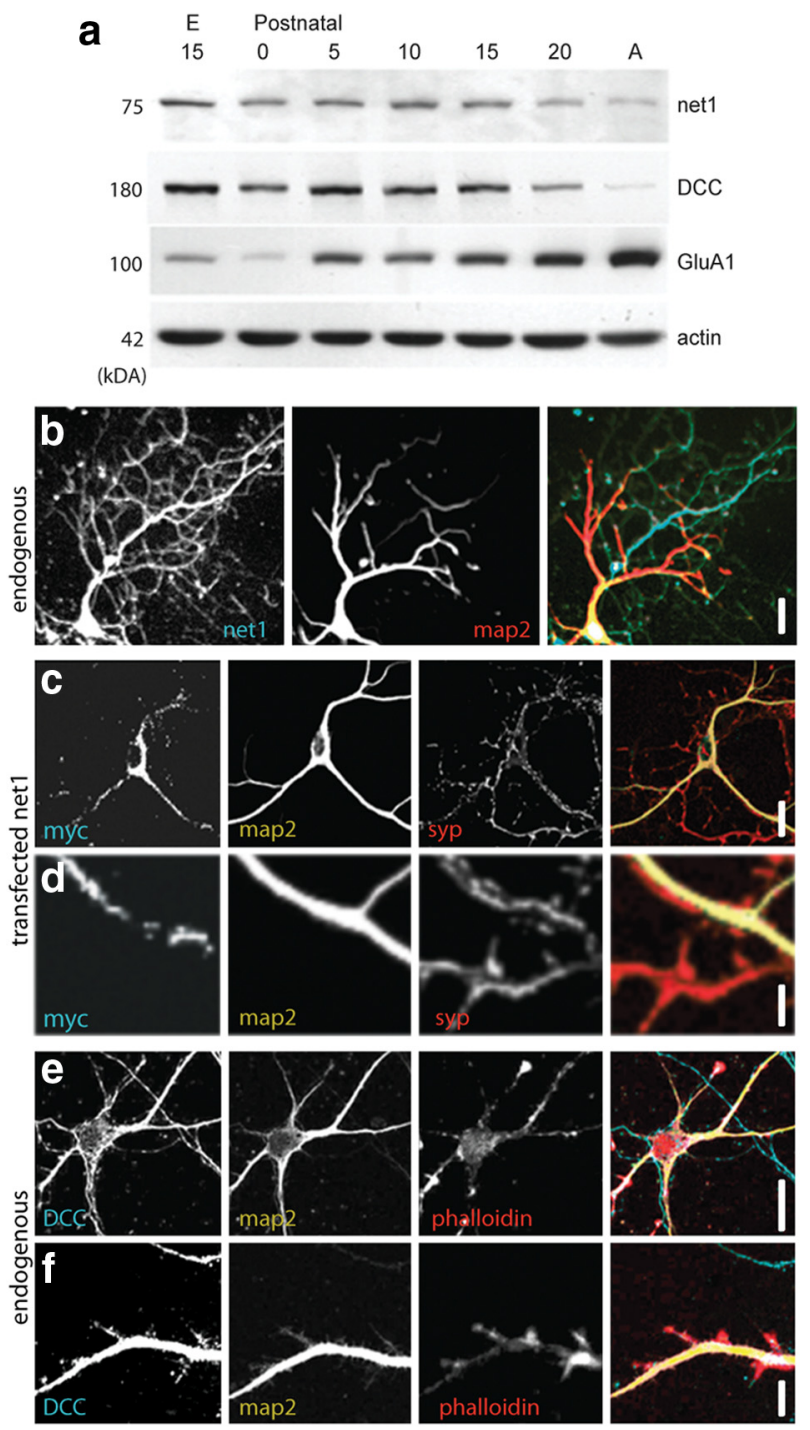
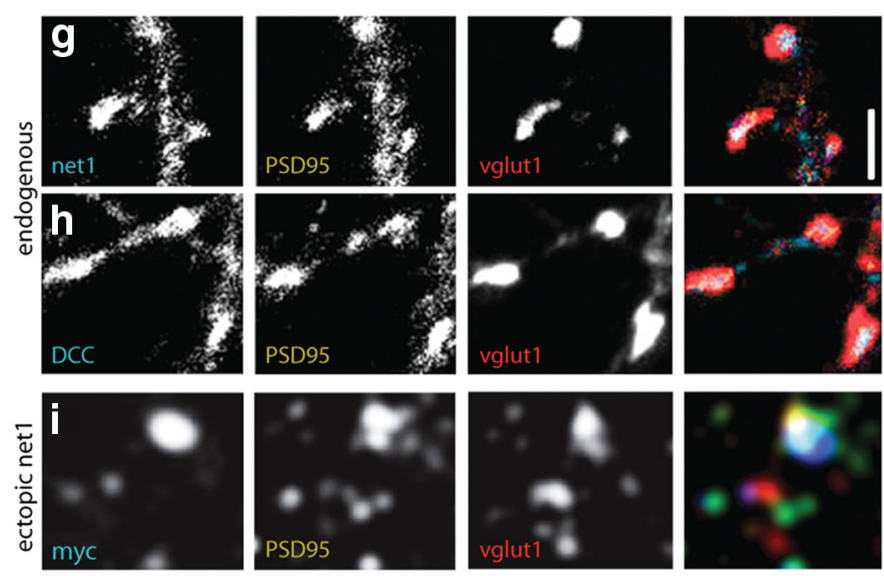

j

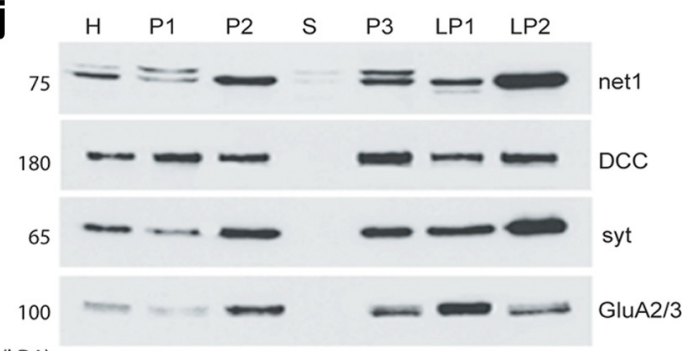

(kDA)
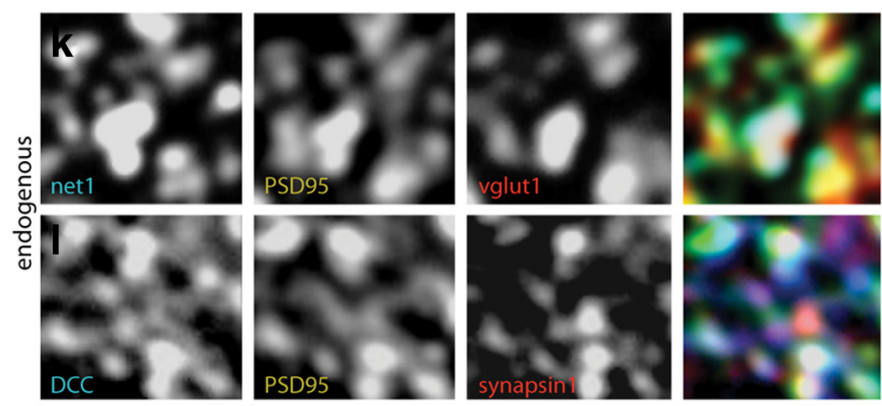

Figure 1. Netrin-1 and DCC are expressed by cortical neurons during synapse formation and are enriched at cortical synapses. $\boldsymbol{a}$, Western blot analysis of cortical homogenates derived following a developmental time course demonstrates that netrin- 1 and DCC are expressed in the neocortex at all ages examined between E15 and adult (A). High levels of netrin- 1 and DCC are present during the period of peak cortical synaptogenesis (P5-P20). $\boldsymbol{b}$, Immunostaining 12 DIV dissociated cortical neurons for endogenous protein shows netrin-1 associated with both axons and dendrites. $\boldsymbol{c}, \boldsymbol{d}$, Immunostaining 12 DIV neurons for myc after $6 \mathrm{~h}$ transfection shows newly synthesized netrin-1-myc protein trafficked to dendrites. $\boldsymbol{e}$, $\boldsymbol{f}$, Endogenous DCC is trafficked to axons and dendrites and is seen in F-actin-rich, dynamic protrusions labeled with phalloidin. $\boldsymbol{g}$, $\boldsymbol{h}$, Staining for endogenous protein in 21 DIV neurons shows netrin-1 and DCC immunoreactivity overlaps substantially with markers of glutamatergic synapses. $\boldsymbol{i}$, At 21 DIV, adding soluble recombinant netrin-myc protein results in myc immunoreactivity overlapped with markers of glutamatergic synapses. $\boldsymbol{j}$, Subcellular fractionation of 15-d-old rat cortex reveals that netrin-1 and DCC enrich with synaptosomes. $H$, homogenate; P1, nuclei and cellular debris; P2, crude synaptosome; $S$, cytosol; P3, Golgi, ER, internal membrane; LP1, synaptosomal membrane and mitochondria; LP2, synaptosomal vesicles. $\boldsymbol{k}, \boldsymbol{I}$, Immunostaining in coronal sections from P21 mouse shows netrin-1 ( $\boldsymbol{k}$ ) and DCC (I) staining overlaps substantially with markers of glutamatergic synapses. Scale bars: $\boldsymbol{b}, \boldsymbol{c}, \boldsymbol{e}, 20 \mu \mathrm{m} ; \boldsymbol{d}, \boldsymbol{f}, 5 \mu \mathrm{m} ; \boldsymbol{g}-\boldsymbol{i}, \boldsymbol{k}, \boldsymbol{l}, 2 \mu \mathrm{m}$. GluA1, glutamate AMPA receptor subunit 1; map2, microtubule-associated protein 2; net1, netrin-1; PSD95, postsynaptic density protein 95 kDa; syp, synaptophysin; syt, synaptotagmin; vglut1, vesicular glutamate transporter 1.

15 min before fixation at 9 DIV (Fig. 2a). Significantly more dendritic filopodia were present following 15 min stimulation with netrin-1, and this effect became more pronounced in neurons treated with netrin-1 for $1 \mathrm{~h}, 24 \mathrm{~h}$, or $72 \mathrm{~h}$ (Fig. 2b). Conversely, nfb significantly reduced the density of dendritic filopodia, reaching statistical significance following $24 \mathrm{~h}$ incubation with $\mathrm{nfb}$ and decreasing further following $72 \mathrm{~h}$ (Fig. 2a,b).

Netrin-1 signals through SFKs and mTORC1-dependent mRNA translation to regulate actin

Netrin-1 regulates the organization of the actin cytoskeleton in neurons (Baker et al., 2006; Moore et al., 2007; Lai Wing Sun et al., 2011). Dynamic remodeling of actin between monomeric (Gactin) and filamentous (F-actin) is a critical mechanism underly- ing filopodial protrusion and synapse formation (Dillon and Goda, 2005). We therefore sought to determine whether netrin-1 regulates local neuronal architecture through actin reorganization in cortical neurons during synaptogenesis. To investigate the role of a localized source of netrin-1, such as at the point of initial contact made between a dendrite and an axon, we established an assay in which cultured neurons are presented with netrin-1 protein bound to the surface of $7.3 \mu \mathrm{m}$ polystyrene microspheres (beads). Neurons were infected with semliki-forest virus expressing eGFP-f to visualize fine membrane protrusions, which enwrapped netrin-1 beads within $24 \mathrm{~h}$, forming structures reminiscent of synaptic specializations along the surfaces (Fig. $3 a, b)$. To determine whether netrin-1 would induce the local enrichment of actin, cortical neurons were incubated with 

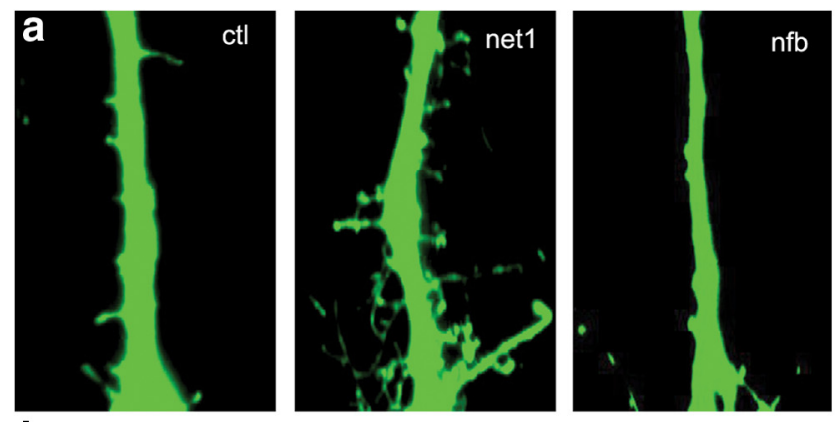

b

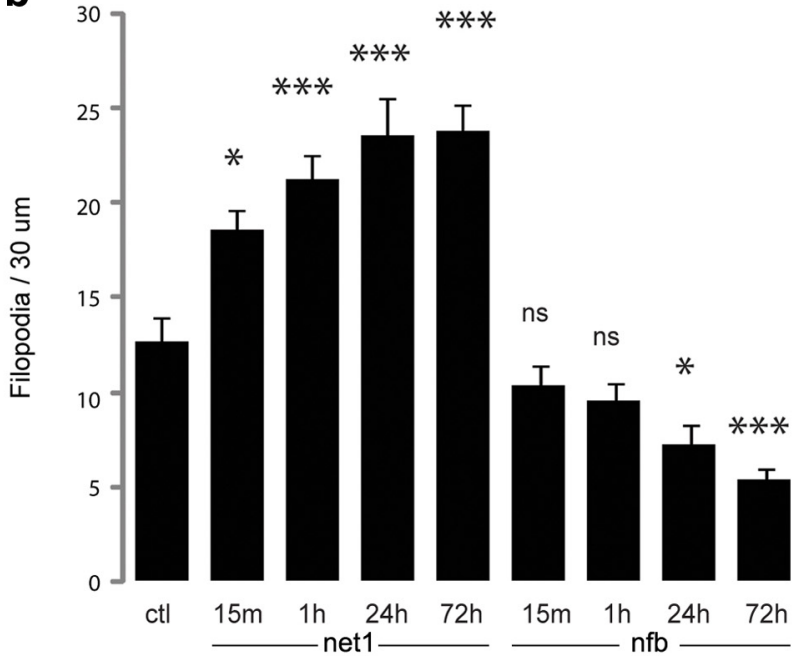

Figure 2. Netrin-1 loss and gain of function modulate the number of dendritic filopodia. $\boldsymbol{a}$, $\boldsymbol{b}$, Cortical neurons were transfected with a CDNA encoding eGFP-f and stimulated with netrin-1 (net1) or netrin-1 function-blocking antibody (nfb) for $72 \mathrm{~h}, 24 \mathrm{~h}, 1 \mathrm{~h}$, or 15 min before fixation at 9 DIV. $\boldsymbol{a}$, Shows an example from each condition at $72 \mathrm{~h}$. $\boldsymbol{b}$, The number of dendritic filopodia along the $30 \mu \mathrm{m}$ of apical dendrite proximal to the cell body (as shown in $\boldsymbol{a}$ ) was quantified ( $\boldsymbol{b}$; $n=20$ cells for each condition; one-way ANOVA, Tukey test). Error bars indicate SEM; ${ }^{*} p<$ $0.05,{ }^{* * *} p<0.001$. Ctl, control.

netrin-1 beads (net1) or control beads not adsorbed with protein (ctl) for 10 or $30 \mathrm{~min}$ before fixation (Fig. $3 c-g$, Tables $1-4$ ). Cells were then stained with Alexa-conjugated phalloidin to visualize F-actin and DNAase I to visualize G-actin (Cramer et al., 2002; Fig. $3 c-g$, Tables 1-4). The distributions of F- and G-actin were analyzed, comparing the fluorescence intensity in the area of neurite (axon or dendrite) in contact with the bead (b) with a comparable area of neurite adjacent (a) to the bead (Fig. $3 d$ ). Netrin-1 induced a localized increase in both phalloidin and DNAase I staining (Fig. $3 d, e$ ). To determine whether the netrin-1-induced increase in actin required DCC, we added a monoclonal antibody to block DCC function ( $\mathrm{dfb}$ ), or an isotype-control antibody (IgG) to cultured cortical neurons before adding beads. Preincubation of cultures with $\mathrm{dfb}$, but not with the control IgG, abolished the netrin-1-induced increases in local phalloidin and DNAase I (Fig. $3 e-g$ ).

Netrin-1 signaling activates SFKs (Li et al., 2004; Liu et al., 2004), which can release $\beta$-actin mRNA from translational inhibition (Hüttelmaier et al., 2005). Local translation of $\beta$-actin mRNA is stimulated by netrin-1 (Chen et al., 2007), and has been implicated in netrin-induced axon chemoattraction (Leung et al., 2006; Welshhans and Bassell, 2011). To determine whether SFK activation is required for netrin-1-induced increases in local G-actin and F-actin in cortical neurons, we added the selective SFK inhibitor (PP2) or an inactive analog (PP3) to cortical neu- rons before adding netrin-1 beads. Indeed, PP2, but not PP3, inhibited the netrin-1-induced increases in DNAase I and phalloidin labeling (Fig. $3 e-g$ ). Finally, to determine whether the local increases in F- and G-actin are dependent on protein synthesis through a pathway requiring mammalian target of rapamycin (mTor), we incubated cortical neurons with rapamycin (rap) concomitant with netrin-1 beads. Rapamycin abolished the netrin-1-induced increases in local G- and F-actin (Fig. 3e-g). Enrichment of active SFKs phosphorylated at tyrosine 416 (Y416; Fig. $3 h, i$ ) and increased protein synthesis (Fig. 3j,k) were also associated with netrin- 1 beads. Together, these findings indicate that netrin-1 locally aggregates and polymerizes actin through a mechanism dependent on DCC, SFK activation, and rapamycinsensitive protein synthesis.

\section{Netrin-1-coated microspheres adhere to cortical neurons}

To better understand how neurons interact with a local source of netrin-1, we performed live imaging of cortical neurons when challenged with beads. While control beads were seen to passively diffuse with convection currents and to only occasionally become immobilized, filopodia elaborated by the neurites of cortical neurons rapidly captured and retained netrin-1-coated beads (Fig. $4 a)$. To quantify the interaction of netrin-1-coated beads and control beads with cortical neurons, we performed an adhesion assay. Beads were incubated with cortical neurons for $1 \mathrm{~h}$ and cell culture wells were then vigorously washed with warm PBS (Fig. $4 b$ ). Whereas only $24 \pm 4 \%$ of control beads remained attached to cortical neurons following washes, $88 \pm 6 \%$ of netrin-1-coated beads remained bound (Fig. $4 b, c$ ), indicating that netrin-1coated beads adhere to cortical neurons. This adhesion requires DCC, as competition with Dfc, a DCC receptor-body chimeric protein (Moore et al., 2008), reduced adhesion to control levels. We then determined whether F-actin reorganization is required for netrin-1-induced adhesion. Addition of latrunculin-A, which inhibits actin polymerization, had no distinguishable effect on the adhesion of netrin-1-coated beads to cortical neurons (Fig. 4c). In contrast, jasplakinolide, which inhibits F-actin depolymerization, abolished the adhesion of netrin-1 beads to cortical neurons (Fig. 4c). Thus, netrin-1 adheres to cortical neurons through a mechanism that requires DCC and F-actin depolymerization.

\section{Local enrichment of synaptic proteins at sites of contact with netrin-1-coated microspheres}

Because netrin-1 regulates filopodium formation and adhesion, processes intimately involved in synaptogenesis (Waites et al., 2005), we sought to determine whether netrin-1 regulates the formation of synapses. Cortical neurons grown at a very low density were incubated for $3 \mathrm{~h}$ with control or netrin- 1 beads and subsequently immunocytochemically labeled for presynaptic and postsynaptic proteins (Fig. 5). Quantification was performed as illustrated in Fig. 3c. All presynaptic proteins assessed, synapsin (syn), synaptophysin (syp), and the vesicular glutamate transporter 1 (vglut 1), were highly enriched at sites of contact between cortical neurons and netrin-1 beads (Fig. $5 a, b, d, e$ ). Intriguingly, postsynaptic proteins PSD95 and the AMPA glutamate receptor subunit GluA1 were also significantly enriched at sites of netrin-1 bead contact (Fig. $5 c, f, g$ ). The aggregation of both presynaptic and postsynaptic proteins depends on signaling through DCC, SFKs, and rapamycin-sensitive protein synthesis, as incubation of cortical neurons with $\mathrm{dfb}, \mathrm{PP} 2$, or rapamycin abolished the effect of netrin-1 microspheres on local synaptic protein enrichment (Fig. $5 d-g$ ). Unlike adhesion, the enrichment of 

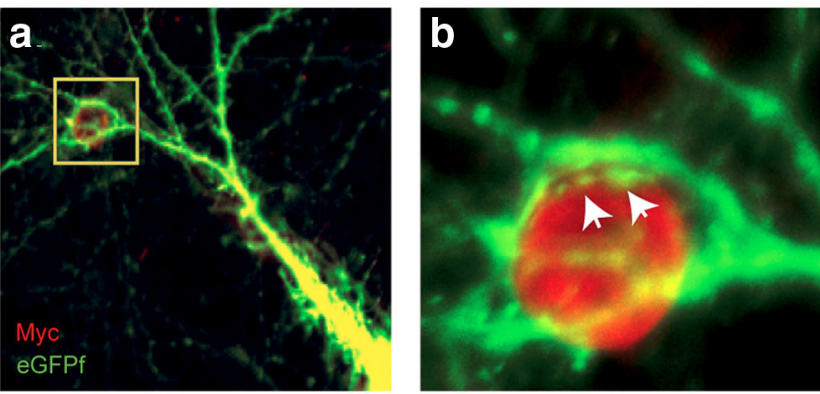

C

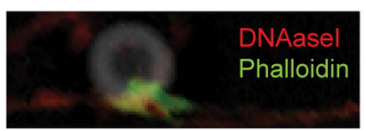

e

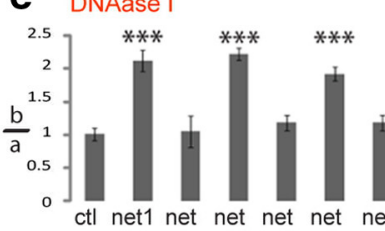

dfb IgG PP2 PP3 rap
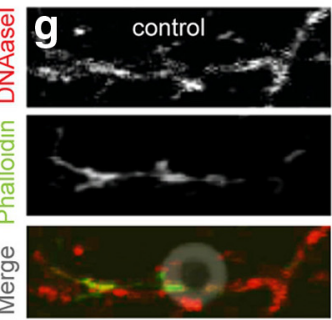

h
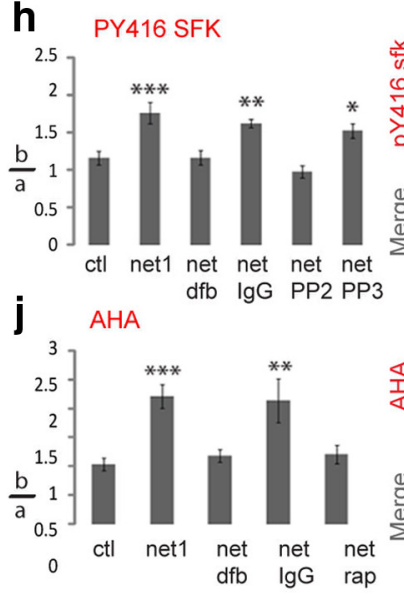
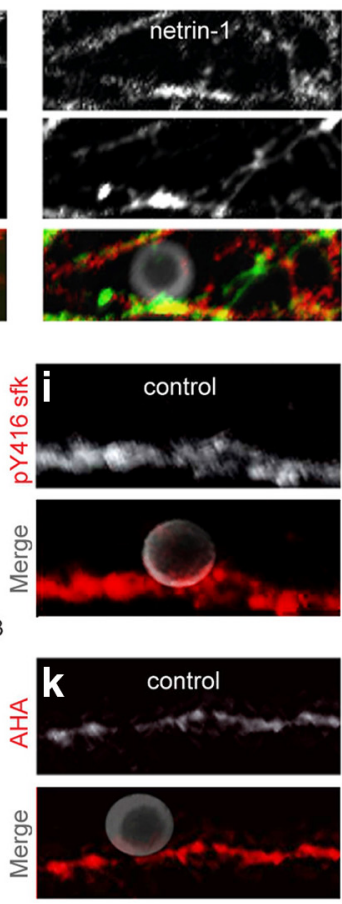
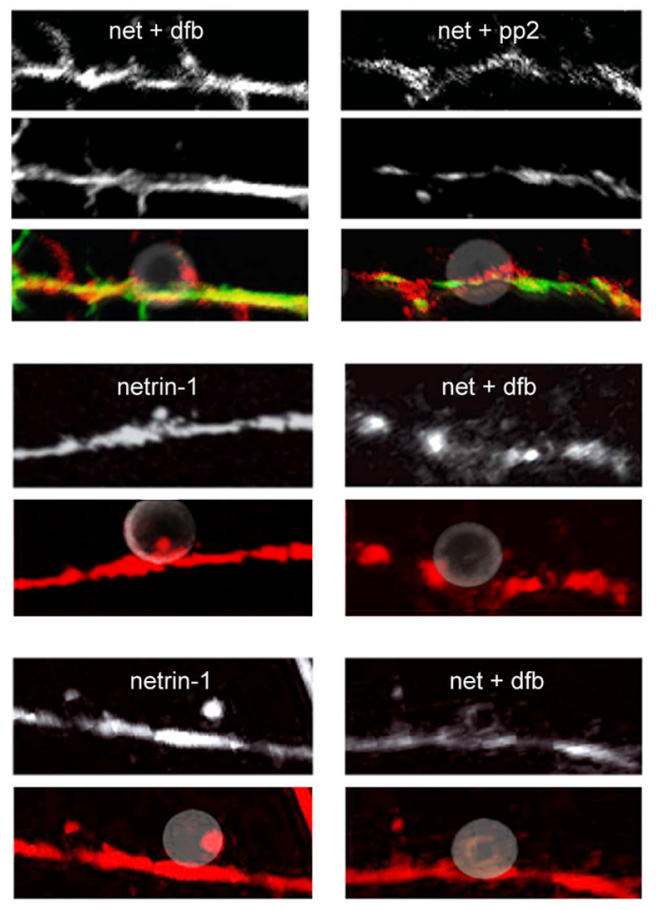

d

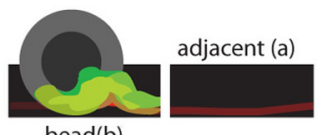

f Phalloidin

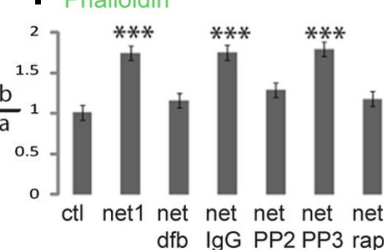

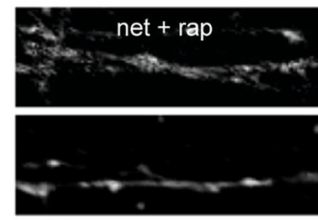
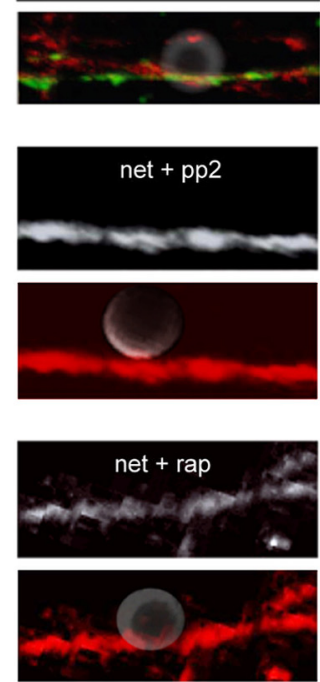

Figure 3. Netrin-1 locally enriches and reorganizes actin through Src family kinase signaling and rapamycin-sensitive protein synthesis. $\boldsymbol{a}, \boldsymbol{b}$, In cortical neurons infected with semliki-forest virus expressing eGFP-f fine membrane protrusions can be seen interacting with myc-netrin-1 adsorbed microspheres following $24 \mathrm{~h}$ incubation from 11 to 12 DIV. Arrowheads indicate membrane protrusions morphologically similar to synaptic specializations. The fluorescence intensities along $10 \mu \mathrm{m}$ of neurite in contact with a bead and immediately adjacent to the bead were quantified, as shown in the data in cand illustration of the quantification in $\boldsymbol{d}$. Values are expressed as intensity of fluorescence at the beads/adjacent (b/a) in $\boldsymbol{e}, \boldsymbol{f}, \boldsymbol{h}$, and $\boldsymbol{j} . \boldsymbol{e}, \boldsymbol{f}$, Quantification of $\mathrm{G}$-actin $(\boldsymbol{e})$ and F-actin $(\boldsymbol{f})$ in 12 DIV neurons incubated with control or netrin- 1 beads for $30 \mathrm{~min}$, in the absence or presence of DCC function-blocking antibody (dfb), isotype-control antibody (IgG), inhibitor of SFKs (PP2), an inactive analog of PP2 (PP3), or rapamycin (rap), and then stained with DNAase I to visualize $G$-actin and phalloidin to visualize F-actin ( $\boldsymbol{g} ; n=20$ beads per condition; one-way ANOVA, Tukey Test). $\boldsymbol{h}$, Quantification of staining for active SFK (pY416) in 12 DIV neurons incubated for 30 min with control or netrin-1 beads in the absence or presence of dfb, IgG, PP2, or PP3 (i; $n=16$ beads per condition; one-way ANOVA, Tukey test). $\boldsymbol{j}$, Analysis of novel protein synthesis in 12 DIV neurons incubated with beads for 30 min (ctl, $n=28 ;$ net1, $n=25$; net $1+$ dfb, $n=20 ;$ net $1+$ $\operatorname{lgG}, n=22$; net1 + rapamycin, $n=22$; one-way ANOVA, Tukey test). $\boldsymbol{k}$, Examples of AHA click chemistry for newly synthesized protein in cultures incubated with control or netrin- 1 beads for 30 min in the absence or presence of dfb, IgG, or rapamycin. ${ }^{*} p<0.05,{ }^{* *} p<0.01$, and ${ }^{* * *} p<0.001$. Error bars indicate SEM.

Table 1. Quantification of DNAase I and phalloidin intensity $(b / a \pm$ SEM) following 10 and 30 min incubation of netrin- 1 beads with cortical neurons

\begin{tabular}{|c|c|c|c|c|c|c|c|}
\hline & $\mathrm{Ctl}$ & Net1 & Net1 DFB & Net1 lgG & Net1 PP2 & Net1 PP3 & Net1 Rapa \\
\hline \multicolumn{8}{|l|}{ DNAase I } \\
\hline $10 \mathrm{~min}$ & $1.08 \pm 0.10$ & $1.60 \pm 0.10$ & $1.00 \pm 0.14$ & $1.51 \pm 0.16$ & $1.19 \pm 0.06$ & $1.65 \pm 0.12$ & $1.14 \pm 0.11$ \\
\hline $30 \min$ & $1.01 \pm 0.13$ & $1.75 \pm 0.10$ & $1.16 \pm 0.09$ & $1.75 \pm 0.12$ & $1.29 \pm 0.13$ & $1.79 \pm 0.09$ & $1.18 \pm 0.09$ \\
\hline \multicolumn{8}{|l|}{ Phalloidin } \\
\hline $10 \min$ & $0.96 \pm 0.11$ & $1.77 \pm 0.27$ & $0.95 \pm 0.14$ & $1.73 \pm 0.25$ & $1.05 \pm 0.15$ & $1.78 \pm 0.29$ & $1.35 \pm 0.18$ \\
\hline $30 \mathrm{~min}$ & $1.00 \pm 0.10$ & $2.12 \pm 0.16$ & $1.05 \pm 0.24$ & $2.22 \pm 0.09$ & $1.18 \pm 0.11$ & $1.92 \pm 0.12$ & $1.18 \pm 0.11$ \\
\hline
\end{tabular}

synaptic proteins was abolished by addition of latrunculin-A, but was not sensitive to jasplakinolide (Fig. $5 d-g$ ). Thus, netrin-1-coated beads induce the local enrichments of presynaptic and postsynaptic proteins through a mechanism dependent on DCC, SFKs, rapamycin-sensitive protein synthesis, and actin polymerization.
Table 2. Quantification of AHA intensity (b/a \pm SEM) following 10 and 30 min incubation of netrin- 1 beads with cortical neurons

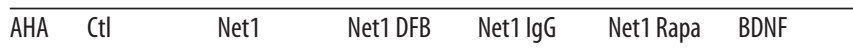

$\begin{array}{lllllll}10 \min & 1.09 \pm 0.14 & 1.61 \pm 0.19 & 1.13 \pm 0.16 & 1.56 \pm 0.07 & 1.12 \pm 0.08 & 1.41 \pm 0.19\end{array}$

$30 \min 1.03 \pm 0.112 .21 \pm 0.201 .18 \pm 0.112 .13 \pm 0.24 \quad 1.21 \pm 0.151 .43 \pm 0.13$ 
Recruitment of presynaptic and postsynaptic proteins to sites of contact with netrin-1-coated microspheres

DCC is enriched at cortical synapses and netrin-1-coated beads adhere to cortical neurons in a DCC-dependent manner. Thus, it is possible that netrin-1-coated beads associate with synaptic proteins due to the selective adhesion of netrin-1 beads to preexisting synaptic specializations. This seems unlikely because jasplakinolide blocked adhesion (Fig. 4), but did not eliminate the association of netrin-1 beads with enrichments of synaptic protein (Fig. 5). To directly determine whether netrin-1 locally recruits synaptic proteins, netrin-1 beads were precisely placed adjacent to cortical neurites at positions where synaptic specializations did not previously exist, using beads attached to the cantilever of an AFM (Lucido et al., 2009). Before contact with control or netrin-1 beads, synaptophysinGFP or PSD95-GFP transfected neurons were imaged for $10 \mathrm{~min}$ to collect baseline fluorescence intensity values and identify a site to initiate bead contact that did not contain stable fluorescent puncta. Cortical neurons were then contacted with beads and imaged for $\sim 90 \mathrm{~min}$ and all intensity values were normalized to baseline images (Fig. $6 a, b$ ). While control beads had no effect on the localization of synaptophysin-GFP, netrin-1-coated beads induced a steady local accumulation of synaptophysin-GFP over the course of the imaging period (Fig. $6 c, d$ ). Statistical analysis revealed the development of a significant difference from baseline $80 \mathrm{~min}$ after initiating contact with the netrin-1 bead. Thus, a local source of netrin-1 induces the presynaptic aggregation of synaptic vesicles.

To address whether control or netrin-1 beads are capable of locally inducing postsynaptic specializations, and, if so, to determine the time course of induction, PSD95-GFP transfected neurons were contacted with control or netrin-1-coated beads affixed to the AFM cantilever. While control beads had no detected effect on the local content of PSD95GFP (Fig. 6f), netrin-1 beads induced a rapid and stable accumulation of PSD95-GFP (Fig. 6e,f), which statistical analysis indicates became significantly different from baseline within 20 min of initiating contact with the netrin-1 bead. Thus, a local source of netrin-1 induces the rapid aggregation of this key postsynaptic scaffold.

\section{Netrin-1 increases excitatory synapse number, size, and strength}

The above findings provide evidence that netrin- 1 increases the formation of filopodia and promotes contact between axons and dendrites, then locally recruits synapse-associated proteins to sites of contact. To directly address whether modulation of netrin-1 influences the formation of synaptic connections between cortical neurons, we incubated neurons at 11 DIV with netrin-1 (net1) or netrin function-blocking antibody ( $\mathrm{nfb}$ ) for $24 \mathrm{~h}$, fixed, and labeled immunocytochemically for excitatory presynaptic and postsynaptic markers (Fig. 7). To assess the consequences of gain or loss of netrin- 1 function, the density and size of vglut1-positive puncta, PSD95-positive puncta, and vglut1/PSD95-positive puncta, were
Table 3. Quantification of pYSFK intensity $(b / a \pm$ SEM) following 10 and $30 \mathrm{~min}$ incubation of netrin- 1 beads with cortical neurons

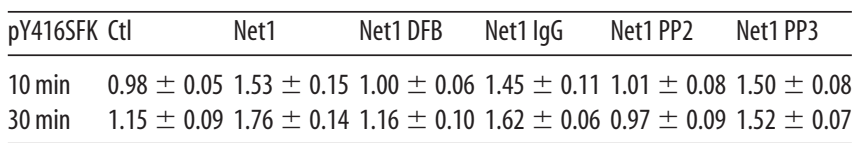

Table 4. Quantification of SFK intensity (b/a \pm SEM) following 10 and $30 \mathrm{~min}$ incubation of netrin- 1 beads with cortical neurons

\begin{tabular}{lllll}
\hline SFKs & Ctl & Net1 & Net1 PP2 & Net1 PP3 \\
\hline $10 \min$ & $1.10 \pm 0.07$ & $1.57 \pm 0.08$ & $1.33 \pm 0.07$ & $1.54 \pm 0.09$ \\
$30 \min$ & $1.16 \pm 0.08$ & $1.66 \pm 0.11$ & $1.43 \pm 0.08$ & $1.70 \pm 0.08$ \\
\hline
\end{tabular}

(a)
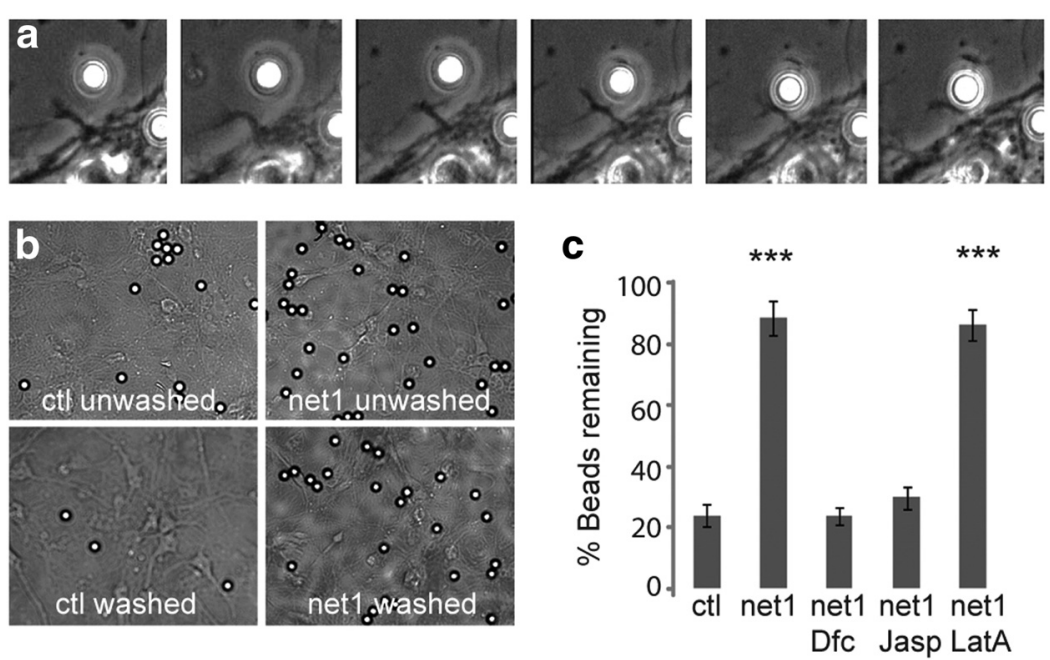

Figure 4. Cortical neurons adhere to netrin-1-coated beads. $\boldsymbol{a}$, Time-lapse imaging of $11 \mathrm{DIV}$ cortical neuron growth cones .

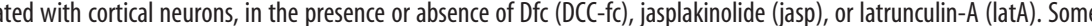
igorously washed to remove nonadherent beads, while others were unwashed to serve as loading controls (unwashed). Quantification of the percentage of beads remaining is shown in c ( $n=40$ examples per condition). One-way ANOVA, Tukey test; error bars indicate SEM; ${ }^{* * *} p<0.001$.

quantified along $30 \mu \mathrm{m}$ of apical dendrite proximal to the cell body of neurons with pyramidal morphology (Fig. 7a). While netrin-1 stimulation significantly enhanced the number and size of vglut1-positive (Fig. 7b,e), PSD95-positive (Fig. 7c,f), and colocalized puncta (Fig. $7 d, g$ ), nfb significantly reduced the number and size of vglut 1-positive (Fig. 7b,e), PSD95-positive (Fig. $7 c, f$ ), and colocalized puncta (Fig. $7 d, g$ ). We conclude that netrin-1 regulates the number and size of excitatory synapses identified immunocytochemically.

To determine whether these changes reflect alterations in synaptic function, we measured miniature EPSCs (mEPSCs) from 12 to 13 DIV cortical neurons treated with ectopic netrin-1 or $\mathrm{nfb}$ at 11 DIV (Fig. 8a-f). Consistent with the analysis of synaptic puncta, netrin-1 stimulation decreased the interevent interval between mEPSCs (increased the frequency; Fig. $8 a-c$ ) and enhanced the amplitude of mEPSCs (Fig. $8 d-f$ ), while inhibiting netrin-1 with nfb significantly reduced the frequency (Fig. $8 a-c$ ) and amplitude (Fig. 8d-f) of mEPSCs.

Netrin-1-null mice die at birth, well before the vast majority of cortical synaptogenesis occurs. To determine whether genetic deletion of netrin-1 modulates the formation of excitatory synapses and whether postsynaptic expression of netrin-1 mediates the effect on synaptogenesis, we made cultures of cortical neurons 

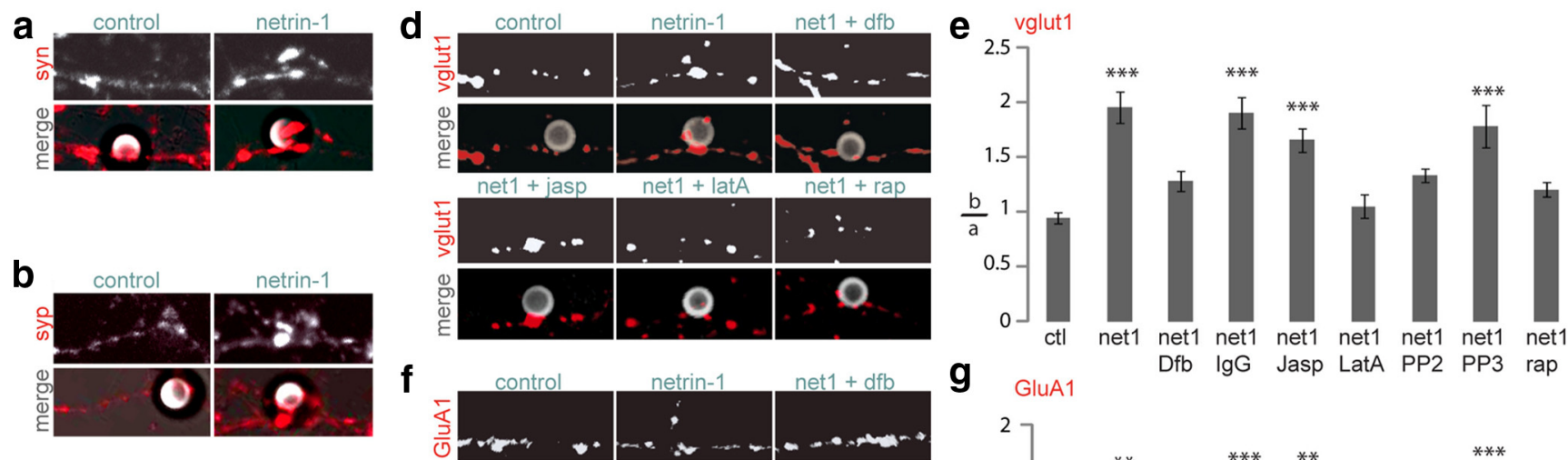

g
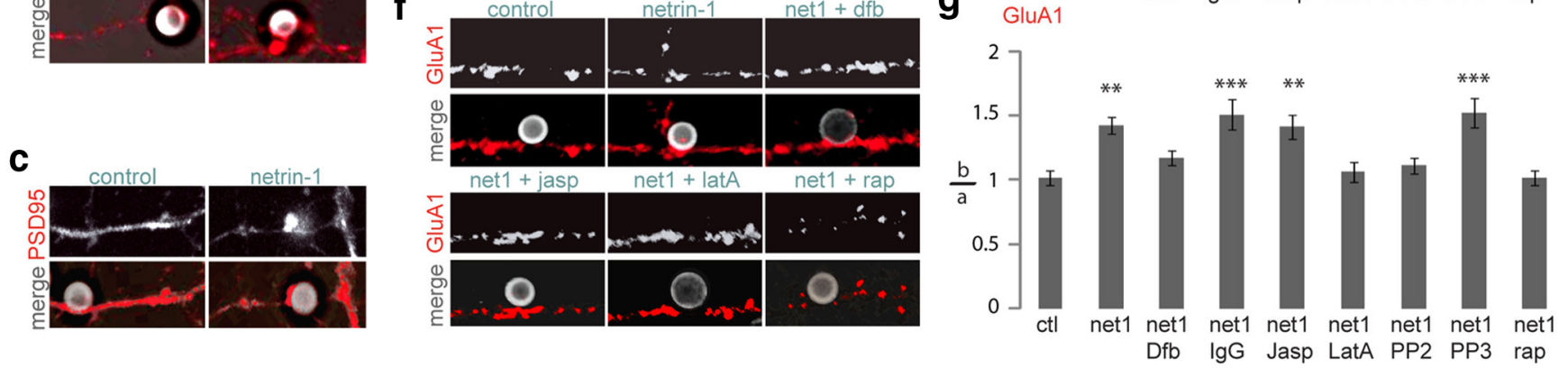

Figure 5. Netrin-1 beads are associated with presynaptic and postsynaptic clusters. Cortical neurons, $14 \mathrm{DIV}$, were incubated for $3 \mathrm{~h}$ with control or netrin-1-coated beads and following fixation were labeled immunocytochemically for synapsin $(\boldsymbol{a})$, synaptophysin $(\boldsymbol{b})$, or PSD95 (c). Cortical neurons incubated for $3 \mathrm{~h}$ with control or netrin-1-coated beads in the absence or presence of dfb, lgG, jasplakinolide, latrunculin-A, PP2, PP3, or rapamycin were stained immunocytochemically following fixation for vglut 1 (d) or GluA1 ( $\boldsymbol{f}$ ). Analysis of relative vglut 1 staining intensity at beads is shown in $\boldsymbol{e}\left(n=20\right.$ beads per condition, one-way ANOVA, Tukey test) and of GluA1 in $\boldsymbol{g}\left(n=20\right.$ beads per condition, one-way ANOVA, Tukey test). Error bars indicate SEM; ${ }^{* *} p<0.01$, ${ }^{* * *} p<0.001$.

a

Baseline $(\alpha)$

C
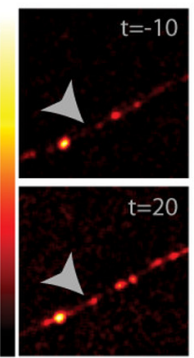

e

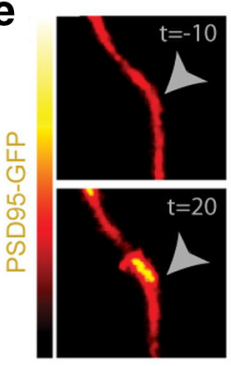
Bead Contact $(\beta)$

$\mathrm{t}=0$
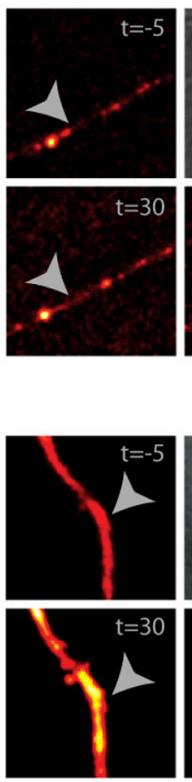
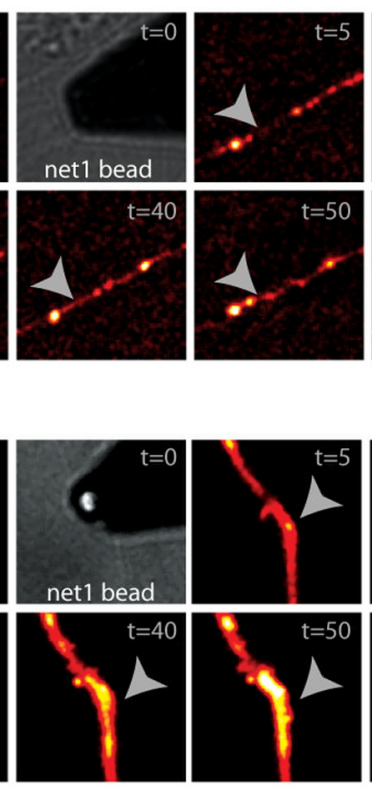
Bead Remove $\mathrm{t}=90 \mathrm{~min}$
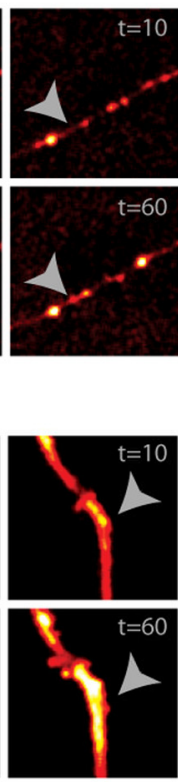

b

$$
i=\frac{\mathrm{i}_{\mathrm{t}}}{\mu \mathrm{i}_{\alpha}}
$$

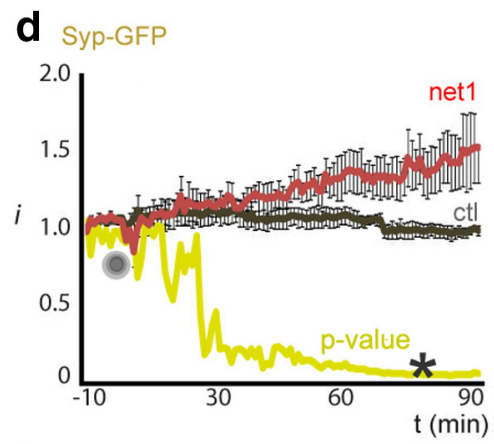

f

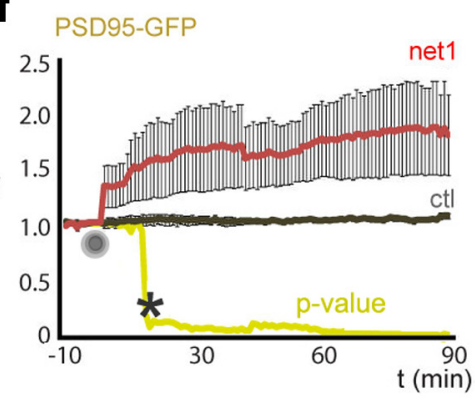

Figure 6. Recruitment of presynaptic and postsynaptic proteins into clusters adjacent to netrin-1-coated beads applied with AFM. $\boldsymbol{a}$, Cortical neurons, 12 to 14 DIV, transfected with synaptophysin-GFP or PSD95-GFP were imaged for 10 min before contact and for 90 min following contact of control or netrin-1 beads with synaptophysin-GFP expressing axons or PSD95-GFP expressing dendrites. $\boldsymbol{b}$, Fluorescence intensity at the site of bead contact at each time point was normalized to average baseline intensity of the same location. $\boldsymbol{c}$, Examples of synaptophysin-GFP before and after netrin- 1 bead contact at $t=0 . \boldsymbol{d}$, Normalized intensity values are shown for synaptophysin-GFP (ctl, $n=3 ; n$ net $1, n=5)$. The gray circle indicates the time of bead contact and yellow trace indicates $p$ value generated by REML analysis. Data were pooled into bins of 10 min duration and a two-way repeated-measures ANOVA with Bonferroni post hoc test used to calculate the significance of differences between baseline and post-treatment conditions, revealing a significant difference in the intensity of synaptophysin-GFP from baseline 80 min after contact with a netrin-1 bead. $\boldsymbol{e}$, Example of experiments using the AFM to contact PSD95-GFP transfected neurons with a netrin- 1 bead. $\boldsymbol{f}$, Normalized intensity values plotted for PSD95-GFP. Netrin-1 beads induce significant local levels of PSD95-GFP within $20 \mathrm{~min}(\mathrm{ctl}, n=3$; net1, $n=5)$. 
a

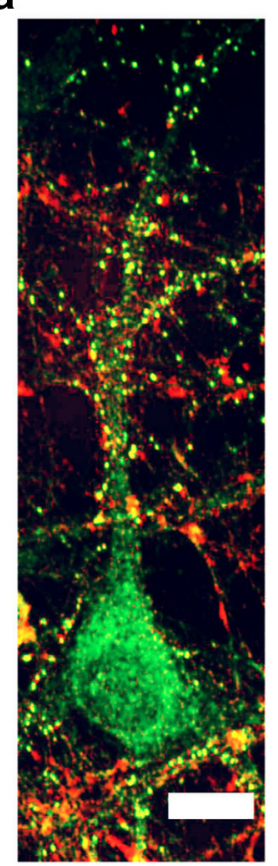

b

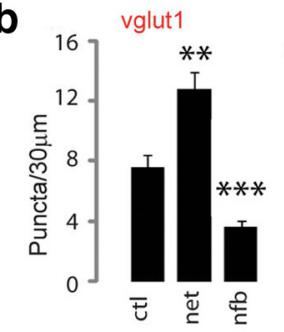

e

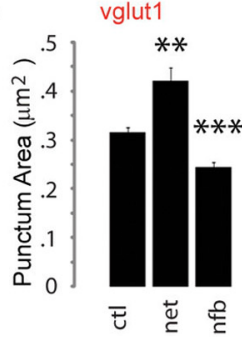

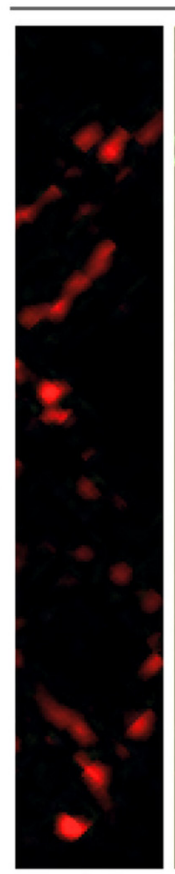

vglut1

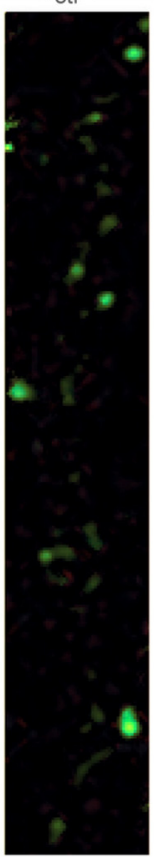

PSD95

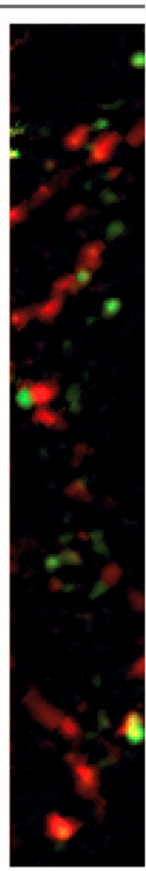

merge

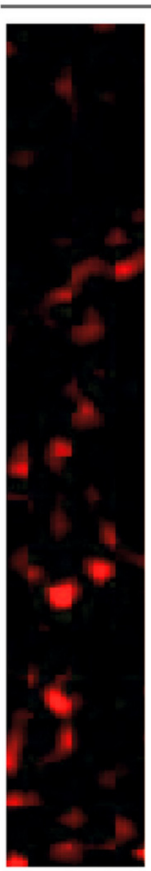

vglut1

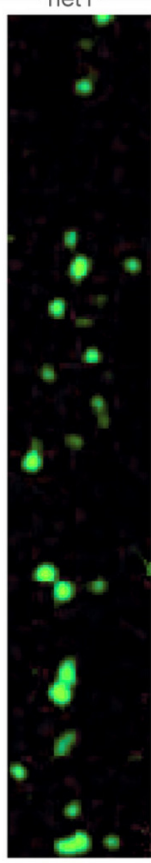

PSD95

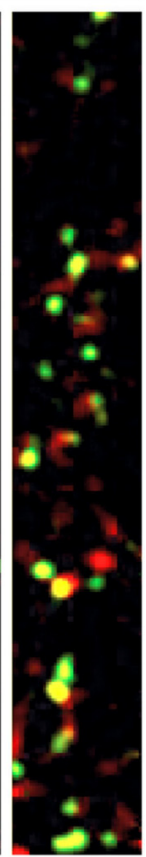

merge

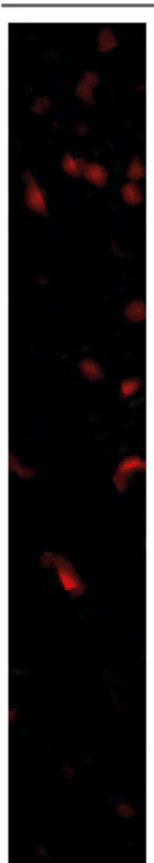

vglut1

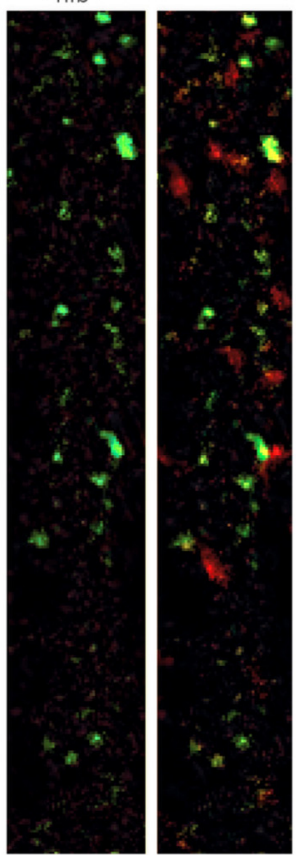

PSD95

merge

d colocalized
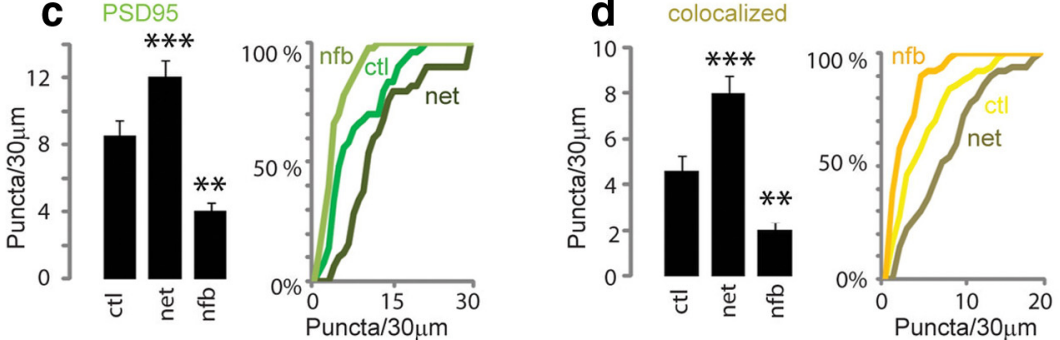

g

olocalized
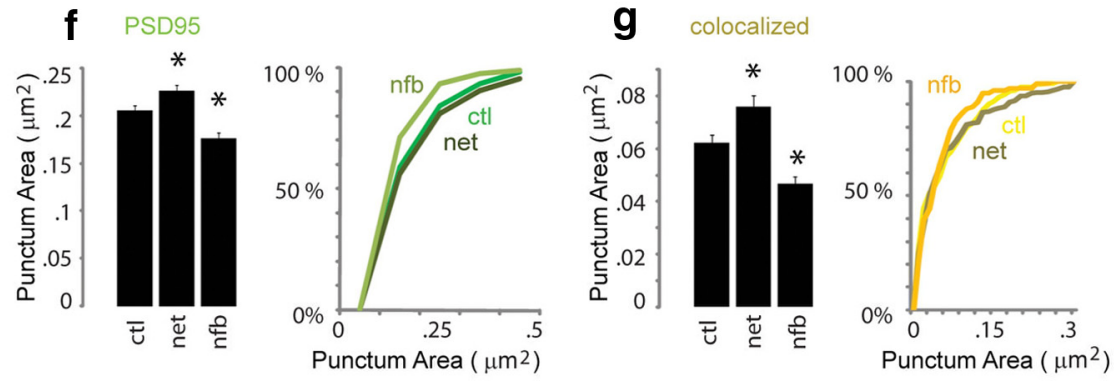

Figure 7. Netrin-1 regulates excitatory synapse number and size. $a$, Cortical neurons incubated with netrin- 1 (net 1 ) or netrin-function blocking antibody (nfb) for $24 \mathrm{~h}$ from $12 \mathrm{to} 13 \mathrm{DIV}$ were immunostained for vglut1 and PSD95 and neurons with pyramidal morphology imaged, as shown in the leftmost image. The $30 \mu \mathrm{m}$ most proximal to the soma of the most prominent dendrite was selected, and background was removed to reveal puncta. Examples of prepared images of $30 \mu \mathrm{m}$ proximal dendrite are shown for control (ctl), netrin- 1 , and nfb conditions. The number ( $\boldsymbol{b}$ ) and size $(\boldsymbol{e})$ of vglut1, PSD95 $(\boldsymbol{c}, \boldsymbol{f})$, and colocalized puncta $(\boldsymbol{d}, \boldsymbol{g})$ were analyzed. Histograms in $\boldsymbol{b}-\boldsymbol{g}$ indicate population means with cumulative probability distributions on right $(n=30$ cells per condition, one-way ANOVA, Tukey test). Error bars indicate SEM; ${ }^{*} p<0.05,{ }^{* *} p<0.01,{ }^{* * *} p<0.001$. Scale bar, $\boldsymbol{a}, 15 \mu \mathrm{m}$.

from E18 netrin-1-null embryos, transfected with either eGFP-f and netrin-1 or eGFP-f alone at 11 DIV, and recorded from transfected neurons with pyramidal morphology at 12-13 DIV. Both the frequency (Fig. $8 g-i$ ) and amplitude (Fig. $8 j-l$ ) of mEPSCs recorded from netrin-1-null cortical pyramidal neurons were reduced when compared with wild-type neurons. Recordings made from transfected cells indicate that the postsynaptic expression of netrin-1 decreases the interevent interval (IEI) and increases the amplitude of mEPSCs recorded from wild-type and netrin-1-null neurons (Fig. $8 g-l$ ).

We next recorded mEPSCs from cultured cortical neurons derived from DCC-null embryos and identified a striking de- crease in frequency in the absence of DCC (Fig. 8m-o). The ectopic addition of netrin-1 protein to DCC-null neurons at 11 DIV resulted in a small, albeit significant, decrease in mEPSC IEI (Fig. $8 m-o$ ). These results indicate that DCC is critical for determining baseline values of mEPSC frequency and that other signaling mechanisms can modestly enhance mEPSC frequency in response to ectopic netrin-1 in the absence of DCC (Fig. $8 m-o$ ). In contrast, DCC is not required for baseline values of mEPSC amplitude and addition of netrin-1 to DCC-null neurons results in a small increase in mEPSC amplitude (Fig. $8 p-r$ ). These findings provide functional electrophysiological and genetic evidence that netrin-1 and DCC promote the formation of excitatory synapses between developing 
a

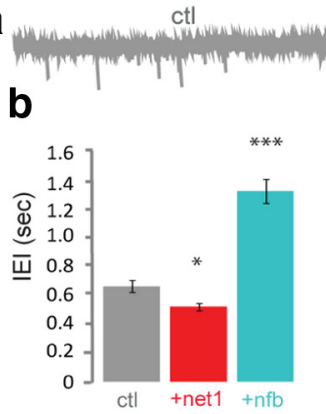

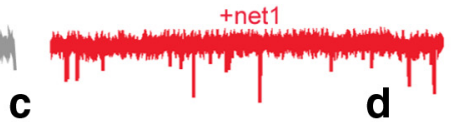

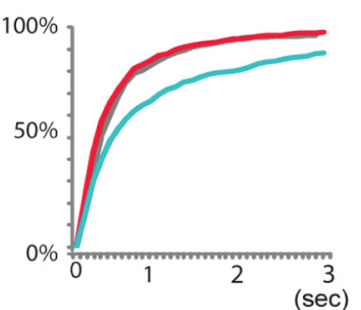

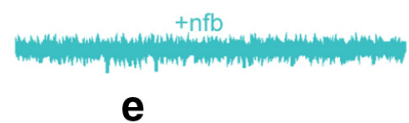

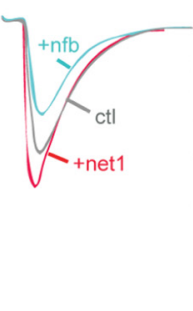

e

f

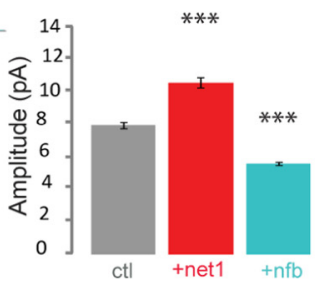

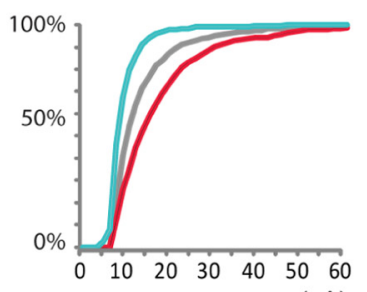

(pA)
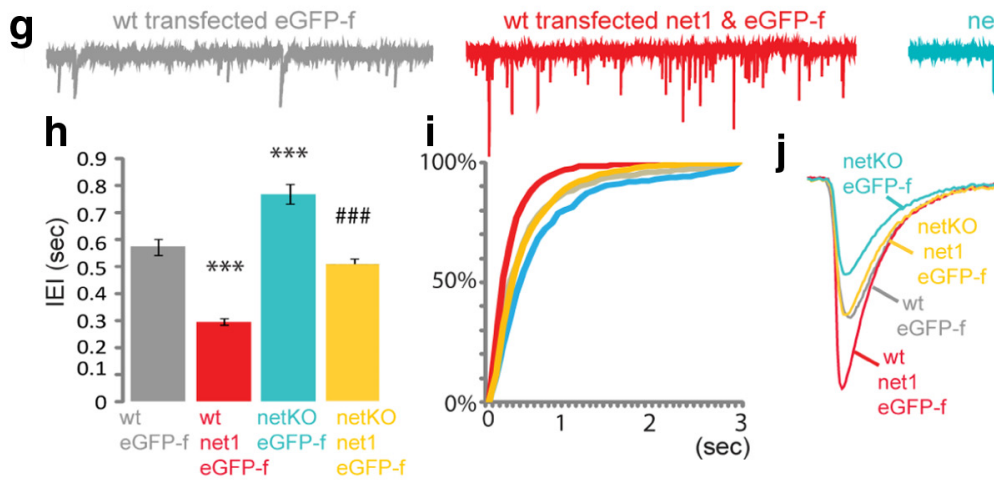

netKO transfected eGFP-f
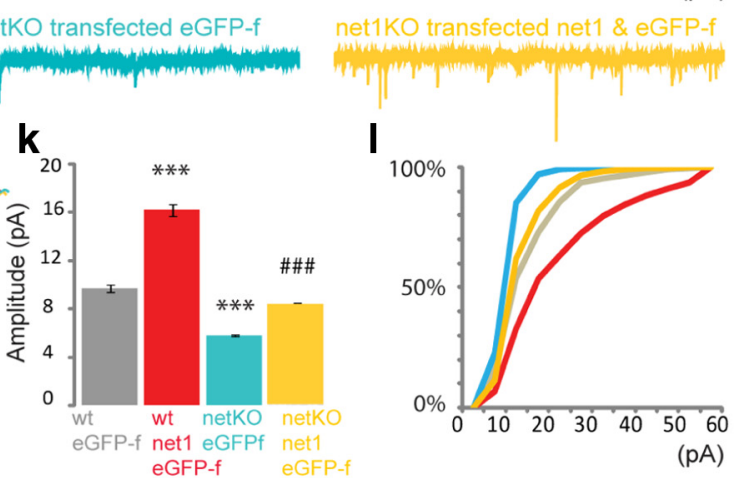

m
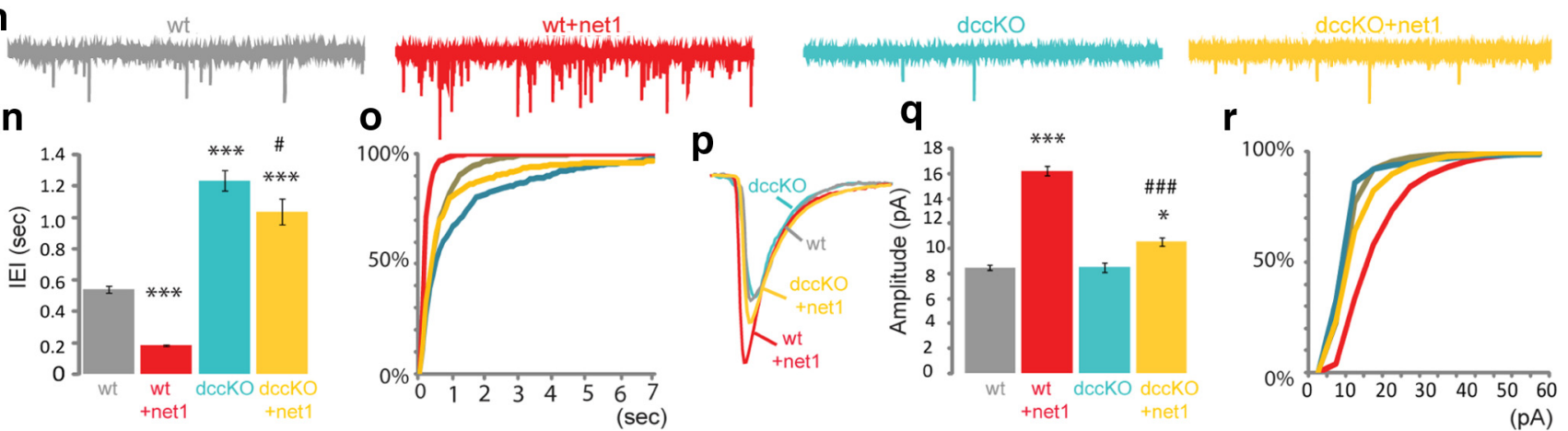

Figure 8. Netrin-1 regulates the frequency and amplitude of synapses in developing cortical pyramidal neurons. $\boldsymbol{a}$, Sample traces from whole-cell patch-clamp analysis of $12-13$ DIV neurons selected for pyramidal morphology, which had been stimulated with netrin-1 (net1) or netrin function-blocking antibody (nfb) at 11 DIV. Average IEls between mEPSCs are indicated in $\boldsymbol{b}$ and cumulative probability distributions in c. Averaged traces are shown for each condition in $\boldsymbol{d}$. Average amplitude for each condition is indicated in $\boldsymbol{e}$ and cumulative probability distributions in $\boldsymbol{f}$. $\boldsymbol{g}$, Sample traces from whole-cell patch-clamp analysis of 12-13 DIV pyramidal neurons cultured from the cortex of embryonic netrin-1 mutant mice transfected with eGFP-f or eGFP-f and netrin-1 at 11 DIV. IEl averages are shown in $\boldsymbol{h}$ and cumulative probability distributions in $\boldsymbol{i}$. Averaged mEPSCs are shown for a cell in each condition in $\boldsymbol{j}$, amplitude means indicated in $\boldsymbol{k}$, and cumulative probability distributions in $\boldsymbol{I} \boldsymbol{m}$, Sample traces from whole-cell patch-clamp analysis of 12-13 DIV pyramidal neurons cultured from the cortex of embryonic DCC mutant mice with or without the ectopic addition of netrin- 1 at 11 DIV. IEl averages are shown in $\boldsymbol{n}$ and cumulative probability distributions in $\boldsymbol{o}$. Averaged traces are shown in $\boldsymbol{p}$ for each condition, IEl analysis in $\boldsymbol{q}$, and population distributions in $r$. One-way ANOVA, post hoc Tukey test. Error bars indicate SEM; ${ }^{*} p<0.05,{ }^{* *} p<0.01$, ${ }^{* * *} p<0.001$ with respect to control, \# indicates comparison between third and fourth bars in histograms $\boldsymbol{h}, \boldsymbol{k}, \boldsymbol{n}$, and $\boldsymbol{q}$. ctl, control; wt, wild-type.

cortical neurons, while a DCC-independent mechanism contributes to the effect of netrin-1 on mEPSC amplitude.

\section{Discussion}

Here we show that netrin-1 is expressed by cortical neurons and enriched at cortical synapses in vivo during the early postnatal peak period of synaptogenesis (Micheva and Beaulieu, 1996). Netrin-1 is a secreted protein; however, most netrin-1 isolated from cortical homogenates is associated with insoluble fractions, including the synaptic compartment. This distribution is consistent with previous studies indicating that following secretion, netrin-1 is tightly bound to extracellular matrix and cell surfaces (Baker et al., 2006). We show that in juvenile rodent cortex in vivo, the majority of netrin-1 is closely associated with excitatory synapses. Furthermore, the addition of recombinant netrin-1 protein to cortical neurons in vitro results in its association with synapses, consistent with synaptic enrichment of netrin-1 receptors or netrin binding proteins.

Netrin-1 increases the number of dendritic filopodia, which in addition to previously reported roles in axon sprouting, increases the probability of axon-dendrite contact. DCC, presented by axons and dendrites, mediates netrin-1-dependent adhesion, directs the organization of F-actin, and the nucleation of excitatory synaptic specializations through the local activation of mTORdependent translation and the activation of SFKs. Our gain and loss of function studies indicate that netrin-1 enhances the number and function of excitatory synapses made by cortical pyramidal neurons.

Netrin-1 signaling has been largely studied in relation to axon guidance where it has been shown to direct axon motility by orchestrating the dynamic reorganization of F-actin in axonal 
growth cones. These studies have determined that under basal conditions, the intracellular domain of DCC constitutively binds the adaptor protein Nck1 (also called DOCK; Li et al., 2002), focal adhesion kinase (FAK; Li et al., 2004), and mRNA translation machinery (Tcherkezian et al., 2010). Upon netrin-1 binding, FAK activation recruits the SFKs Src, Fyn, or Lck (Li et al., 2004; Meriane et al., 2004; Ren et al., 2008), leading to Nck1-dependent recruitment of the kinase PAK1, and the RhoGTPases Cdc42 and Rac (Shekarabi and Kennedy, 2002; Shekarabi et al., 2005). Coincident with this, netrin-1 binding DCC activates PI3 kinase (Ming et al., 1999), eIF-4E, and rapamycin-sensitive protein synthesis (Campbell and Holt, 2001). $\beta$-actin mRNA is tethered to and silenced by zipcode binding protein (ZBP1), which is relieved by tyrosine phosphorylation of ZBP by SFKs (Hüttelmaier et al., 2005). Netrin-1 stimulation results in activation of SFKs (Li et al., 2004), translocation of ZBP into filopodia (Leung et al., 2006), relief from translational inhibition, and the local translation of $\beta$-actin mRNA (Campbell and Holt, 2001). Consistent with these studies, our findings demonstrate that in mammalian cortical neurons undergoing synapse formation, netrin-1 locally stimulates the rapid accumulation and reorganization of F-actin by activating SFKs and rapamycin-sensitive protein synthesis. Furthermore, we show that inhibiting DCC, SFKs, or mTOR-dependent protein synthesis blunts netrin-1-induced actin polymerization and the local enrichment of synaptic proteins.

DCC binding to immobilized netrin-1 mediates cell-cell and cell-substrate adhesion (Shekarabi et al., 2005; Moore et al., 2008). Our findings support a model in which netrin-1 activates signaling mechanisms that result in F-actin reorganization and filopodia protrusion to increase the probability of axon-dendrite contact, while simultaneously acting to tether contacts and locally recruit presynaptic and postsynaptic proteins. Cortical neurons adhere to netrin-1 adsorbed microspheres through a mechanism that requires DCC and actin reorganization, and is inhibited by blocking DCC function or disrupting actin dynamics. Thus, the polymerization of F-actin appears to be dispensable for cortical cell adhesion to netrin-1, whereas F-actin disassembly is required. In contrast, the local enrichment of synaptic proteins at netrin-1 microspheres preferentially requires $\mathrm{F}$-actin polymerization. Notably, this is a mechanistic double dissociation between the adhesive and synaptogenic activity of netrin-1. Thus, netrin-1-mediated adhesion may contribute to increasing the frequency of axon-dendrite contacts, but signaling independent of adhesion recruits synaptic proteins. Consistent with this, cells with stabilized F-actin have fewer microsphere-neurite contacts; however, contacts made under these conditions still exhibit local enrichment of synaptic proteins.

Our electrophysiological analysis of mEPSCs indicates that netrin-1 regulates both the number and strength of synaptic connections made between cortical neurons. In contrast, DCC makes an essential contribution to the density of synaptic connections formed, but is dispensable for the synaptic maturation necessary to generate normal mEPSC amplitude. These findings suggest that other signaling mechanisms can compensate for the absence of DCC and partially mediate the more acute effects of ectopic netrin-1 on mEPSC amplitude and the frequency of detectable mEPSCs. Candidate netrin-1 receptors include the four Unc5 homologs A-D expressed in mammals, the DCC paralog neogenin, and dsCAM (Lai Wing Sun et al., 2011). Netrin-1 also binds heparin sulfate (Serafini et al., 1994; Galko and Tessier-Lavigne, 2000; Kappler et al., 2000), suggesting that it binds heparin sulfate proteoglycans, some of which are known to influence neurotransmitter receptor clustering (Daniels, 2012).
Studies of synapse formation in C. elegans have indicated that the nematode homolog of netrin-1, Unc-6, secreted by a synaptic target instructs presynaptic accumulation of F-actin, active zone proteins, and synaptic vesicles (Stavoe and Colon-Ramos, 2012). While CED-5, CED-10, and MIG-10, homologs of the GEF DOCK180, the RhoGTPase Rac1, and the Rac effector Lamellipodin, respectively, are required for the synaptic nucleation of F-actin and synaptic vesicles, this signaling is dispensable for the aggregation of active zone proteins SYD- 1 and SYD-2 induced by Unc-6. This suggests that Unc-6 activates at least two independent signaling pathways to cluster presynaptic vesicles and recruit active zone scaffolding proteins during synaptogenesis in C. elegans. In mammalian cortical neurons, we observe robust synaptogenic effects of netrin-1 on both presynaptic and postsynaptic domains, with PSD95-GFP accumulating more rapidly at AFMpresented netrin-1 beads than synaptophysin-GFP. Consistent with netrin-1 influencing the development of both axonal and dendritic faces of excitatory synapses, loss or gain of netrin-1 modulates the number and size of PSD95 and vglut1 clusters, as well as the amplitude and frequency of mEPSCs, often interpreted as measures of postsynaptic and presynaptic function, respectively.

Studies performed in invertebrates indicate that in some cases netrins can inhibit the formation of synaptic specializations, excluding presynaptic protein from dendrites and axons (Poon et al., 2008). Netrins are well known to be multifunctional during embryonic development, attracting some axons while repelling others. The findings we report here identify a role promoting excitatory synapse formation and function in developing cortical neurons; these studies do not, however, rule out the possibility that netrin-1 may inhibit or restrict synapse formation in the mammalian brain in other cellular contexts.

Synaptic adhesion molecules and the extracellular matrix are emerging as potent regulators of excitatory synapses in the CNS, orchestrating the recognition of target structures, arborization, axon-dendrite contact, synapse initiation, stabilization, and maturation. Our findings demonstrate that netrin-1 and DCC are present at synapses in vivo during the period of cortical circuit formation and identify netrin-1 as a potent synaptogenic molecule for the formation of excitatory synapses between cortical neurons.

\section{References}

Alexander M, Chan KK, Byrne AB, Selman G, Lee T, Ono J, Wong E, Puckrin R, Dixon SJ, Roy PJ (2009) An UNC-40 pathway directs postsynaptic membrane extension in Caenorhabditis elegans. Development 136:911922. CrossRef Medline

Baker KA, Moore SW, Jarjour AA, Kennedy TE (2006) When a diffusible axon guidance cue stops diffusing: roles for netrins in adhesion and morphogenesis. Curr Opin Neurobiol 16:529-534. CrossRef Medline

Campbell DS, Holt CE (2001) Chemotropic responses of retinal growth cones mediated by rapid local protein synthesis and degradation. Neuron 32:1013-1026. CrossRef Medline

Chen Z, Holt TG, Pivnichny JV, Leung K (2007) A simple in vitro model to study the stability of acylglucuronides. J Pharmacol Toxicol Methods 55:91-95. CrossRef Medline

Colón-Ramos DA, Margeta MA, Shen K (2007) Glia promote local synaptogenesis through UNC-6 (netrin) signaling in C. elegans. Science 318 : 103-106. CrossRef Medline

Cramer LP, Briggs LJ, Dawe HR (2002) Use of fluorescently labelled deoxyribonuclease I to spatially measure G-actin levels in migrating and nonmigrating cells. Cell Motil Cytoskeleton 51:27-38. CrossRef Medline

Daniels MP (2012) The role of agrin in synaptic development, plasticity and signaling in the central nervous system. Neurochem Int 61:848-853. CrossRef Medline

Dent EW, Barnes AM, Tang F, Kalil K (2004) Netrin-1 and semaphorin 3A 
promote or inhibit cortical axon branching, respectively, by reorganization of the cytoskeleton. J Neurosci 24:3002-3012. CrossRef Medline

Dillon C, Goda Y (2005) The actin cytoskeleton: integrating form and function at the synapse. Annu Rev Neurosci 28:25-55. CrossRef Medline

Galko MJ, Tessier-Lavigne M (2000) Function of an axonal chemoattractant modulated by metalloprotease activity. Science 289:1365-1367. CrossRef Medline

Gallo G (2013) Mechanisms underlying the initiation and dynamics of neuronal filopodia: from neurite formation to synaptogenesis. Int Rev Cell Mol Biol 301:95-156. CrossRef Medline

Goslin K, Banker G (1998) Culturing nerve cells. Cambridge, MA: MIT.

Harter PN, Bunz B, Dietz K, Hoffmann K, Meyermann R, Mittelbronn M (2010) Spatio-temporal deleted in colorectal cancer (DCC) and netrin-1 expression in human foetal brain development. Neuropathol Appl Neurobiol 36:623-635. CrossRef Medline

Hilgenberg LG, Smith MA (2007) Preparation of dissociated mouse cortical neuron cultures. J Vis Exp 562.

Hüttelmaier S, Zenklusen D, Lederer M, Dictenberg J, Lorenz M, Meng X, Bassell GJ, Condeelis J, Singer RH (2005) Spatial regulation of betaactin translation by Src-dependent phosphorylation of ZBP1. Nature 438: 512-515. CrossRef Medline

Huttner WB, Schiebler W, Greengard P, De Camilli P (1983) Synapsin I (protein I), a nerve terminal-specific phosphoprotein. III. Its association with synaptic vesicles studied in a highly purified synaptic vesicle preparation. J Cell Biol 96:1374-1388. CrossRef Medline

Kappler J, Franken S, Junghans U, Hoffmann R, Linke T, Müller HW, Koch KW (2000) Glycosaminoglycan-binding properties and secondary structure of the C-terminus of netrin-1. Biochem Biophys Res Commun 271:287-291. CrossRef Medline

Kennedy TE, Serafini T, de la Torre JR, Tessier-Lavigne M (1994) Netrins are diffusible chemotropic factors for commissural axons in the embryonic spinal cord. Cell 78:425-435. CrossRef Medline

Kennedy TE, Wang H, Marshall W, Tessier-Lavigne M (2006) Axon guidance by diffusible chemoattractants: a gradient of netrin protein in the developing spinal cord. J Neurosci 26:8866-8874. CrossRef Medline

Lai Wing Sun K, Correia JP, Kennedy TE (2011) Netrins: versatile extracellular cues with diverse functions. Development 138:2153-2169. CrossRef Medline

Leung KM, van Horck FP, Lin AC, Allison R, Standart N, Holt CE (2006) Asymmetrical beta-actin mRNA translation in growth cones mediates attractive turning to netrin-1. Nat Neurosci 9:1247-1256. CrossRef Medline

Li W, Lee J, Vikis HG, Lee SH, Liu G, Aurandt J, Shen TL, Fearon ER, Guan JL, Han M, Rao Y, Hong K, Guan KL (2004) Activation of FAK and Src are receptor-proximal events required for netrin signaling. Nat Neurosci 7:1213-1221. CrossRef Medline

Li X, Meriane M, Triki I, Shekarabi M, Kennedy TE, Larose L, Lamarche-Vane N (2002) The adaptor protein Nck-1 couples the netrin-1 receptor DCC (deleted in colorectal cancer) to the activation of the small GTPase Rac1 through an atypical mechanism. J Biol Chem 277:37788-37797. CrossRef Medline

Liu G, Beggs H, Jürgensen C, Park HT, Tang H, Gorski J, Jones KR, Reichardt LF, Wu J, Rao Y (2004) Netrin requires focal adhesion kinase and Src family kinases for axon outgrowth and attraction. Nat Neurosci 7:12221232. CrossRef Medline

Lucido AL, Suarez Sanchez F, Thostrup P, Kwiatkowski AV, Leal-Ortiz S, Gopalakrishnan G, Liazoghli D, Belkaid W, Lennox RB, Grutter P, Garner CC, Colman DR (2009) Rapid assembly of functional presynaptic boutons triggered by adhesive contacts. J Neurosci 29:12449-12466. CrossRef Medline

Manitt C, Nikolakopoulou AM, Almario DR, Nguyen SA, Cohen-Cory S (2009) Netrin participates in the development of retinotectal synaptic connectivity by modulating axon arborization and synapse formation in the developing brain. J Neurosci 29:11065-11077. CrossRef Medline

Meriane M, Tcherkezian J, Webber CA, Danek EI, Triki I, McFarlane S, Bloch-Gallego E, Lamarche-Vane N (2004) Phosphorylation of DCC by
Fyn mediates Netrin-1 signaling in growth cone guidance. J Cell Biol 167:687-698. CrossRef Medline

Micheva KD, Beaulieu C (1996) Quantitative aspects of synaptogenesis in the rat barrel field cortex with special reference to GABA circuitry. J Comp Neurol 373:340-354. CrossRef Medline

Ming G, Song H, Berninger B, Inagaki N, Tessier-Lavigne M, Poo M (1999) Phospholipase C-gamma and phosphoinositide 3-kinase mediate cytoplasmic signaling in nerve growth cone guidance. Neuron 23:139-148. CrossRef Medline

Mitchell KJ, Doyle JL, Serafini T, Kennedy TE, Tessier-Lavigne M, Goodman CS, Dickson BJ (1996) Genetic analysis of Netrin genes in Drosophila: Netrins guide CNS commissural axons and peripheral motor axons. Neuron 17:203-215. CrossRef Medline

Moore SW, Tessier-Lavigne M, Kennedy TE (2007) Netrins and their receptors. Adv Exp Med Biol 621:17-31. CrossRef Medline

Moore SW, Correia JP, Lai Wing Sun K, Pool M, Fournier AE, Kennedy TE (2008) Rho inhibition recruits DCC to the neuronal plasma membrane and enhances axon chemoattraction to netrin 1. Development 135:28552864. CrossRef Medline

Park J, Knezevich PL, Wung W, O'Hanlon SN, Goyal A, Benedetti KL, BarsiRhyne BJ, Raman M, Mock N, Bremer M, Vanhoven MK (2011) A conserved juxtacrine signal regulates synaptic partner recognition in Caenorhabditis elegans. Neural Dev 6:28. CrossRef Medline

Poon VY, Klassen MP, Shen K (2008) UNC-6/netrin and its receptor UNC-5 locally exclude presynaptic components from dendrites. Nature 455:669-673. CrossRef Medline

Ren XR, Hong Y, Feng Z, Yang HM, Mei L, Xiong WC (2008) Tyrosine phosphorylation of netrin receptors in netrin-1 signaling. Neurosignals 16:235-245. CrossRef Medline

Schneider CA, Rasband WS, Eliceiri KW (2012) NIH Image to ImageJ: 25 years of image analysis. Nat Methods 9:671-675. CrossRef Medline

Serafini T, Kennedy TE, Galko MJ, Mirzayan C, Jessell TM, Tessier-Lavigne M (1994) The netrins define a family of axon outgrowth-promoting proteins homologous to C. elegans UNC-6. Cell 78:409-424. CrossRef Medline

Shekarabi M, Kennedy TE (2002) The netrin-1 receptor DCC promotes filopodia formation and cell spreading by activating Cdc42 and Rac1. Mol Cell Neurosci 19:1-17. CrossRef Medline

Shekarabi M, Moore SW, Tritsch NX, Morris SJ, Bouchard JF, Kennedy TE (2005) Deleted in colorectal cancer binding netrin-1 mediates cell substrate adhesion and recruits Cdc42, Rac1, Pak1, and N-WASP into an intracellular signaling complex that promotes growth cone expansion. J Neurosci 25:3132-3141. CrossRef Medline

Smith CJ, Watson JD, VanHoven MK, Colón-Ramos DA, Miller DM 3rd (2012) Netrin (UNC-6) mediates dendritic self-avoidance. Nat Neurosci 15:731-737. CrossRef Medline

Stavoe AK, Colón-Ramos DA (2012) Netrin instructs synaptic vesicle clustering through Rac GTPase, MIG-10, and the actin cytoskeleton. J Cell Biol 197:75-88. CrossRef Medline

Suli A, Mortimer N, Shepherd I, Chien CB (2006) Netrin/DCC signaling controls contralateral dendrites of octavolateralis efferent neurons. J Neurosci 26:13328-13337. CrossRef Medline

Tang F, Kalil K (2005) Netrin-1 induces axon branching in developing cortical neurons by frequency-dependent calcium signaling pathways. J Neurosci 25:6702-6715. CrossRef Medline

Tcherkezian J, Brittis PA, Thomas F, Roux PP, Flanagan JG (2010) Transmembrane receptor DCC associates with protein synthesis machinery and regulates translation. Cell 141:632-644. CrossRef Medline

Waites CL, Craig AM, Garner CC (2005) Mechanisms of vertebrate synaptogenesis. Annu Rev Neurosci 28:251-274. CrossRef Medline

Welshhans K, Bassell GJ (2011) Netrin-1-induced local beta-actin synthesis and growth cone guidance requires zipcode binding protein 1. J Neurosci 31:9800-9813. CrossRef Medline

Zhou L, Martinez SJ, Haber M, Jones EV, Bouvier D, Doucet G, Corera AT, Fon EA, Zisch AH, Murai KK (2007) EphA4 signaling regulates phospholipase Cgammal activation, cofilin membrane association, and dendritic spine morphology. J Neurosci 27:5127-5138. CrossRef Medline 